\title{
O CONCEITO DE COMPORTAMENTO OPERANTE COMO PROBLEMA
}

\section{THE CONCEPT OF OPERANT BEHAVIOR AS A PROBLEM}

\author{
Sílvio Paulo Botomé \\ Universidade FEderal de SANTA Catarina, Brasil
}

\begin{abstract}
RESUMO
Desde antes do artigo de Watson "A Psicologia como um behaviorista a vê" (1913), está em questionamento o que é o objeto de estudo e de intervenção em Psicologia. O questionamento, no âmbito da Filosofia, por Bertrand Russell, em 1927, indicava problemas também com o que foi proposto por Watson naquele manifesto. Skinner e vários cientistas e profissionais que se seguiram a ele deram início ao desenvolvimento do conceito de "comportamento", particularmente o "operante", o qual, junto com o conceito de "contingência de reforçamento", possibilitaram uma grande mudança na concepção do objeto de estudo e trabalho da Psicologia. Tal modificação ainda continua com questões e controvérsias importantes, embora seja a contribuição científica mais consistente, duradoura e coerente com as concepções de Ciência que se configuraram até o final do século XX, para a humanidade. A precisão dos conceitos envolvidos com esses dois termos também é objeto de exames, análises, avaliações e mostram imprecisões e controvérsias várias a resolver como parte dos problemas de desenvolvimento da Análise Experimental do Comportamento e do trabalho dos analistas de comportamento para o desenvolvimento de novos comportamentos relevantes na sociedade. Tais conceitos são examinados como parte da constituição dos conceitos de "comportamento operante", distinto de "resposta", de atividade ou de "contingência de reforçamento". O comportamento como um sistema de interações entre classes de aspectos de um ambiente, classes de atividades de um organismo e classes de aspectos de um ambiente subsequente às atividades desse organismo constitui o objeto de exame desse texto. Talvez o conceito de comportamento ainda seja mais parte do problema do que de uma solução no âmbito do trabalho com tal tipo de fenômeno.

Palavras-chave: comportamento operante, classes de respostas, contingências, contingências de reforçamento, tríplice contingência.
\end{abstract}

\section{ABSTRACT}

Since before the Watson's article "Psychology as a behaviorist views it" is questioning what is the object of study and intervention in Psychology. The inquiry, under Philosophy by Bertrand Russell in 1927, also indicated problems with what was proposed by Watson in that article. Skinner and several scientists and professionals that followed he began to develop the concept of "behavior", particularly the concept of "operant", that also with the concept of "contingency of reinforcement", produced a major change in the concept of object of study and work in psychology. Such change still continues with major issues and controversies, although such change be the most consistent, durable and coherent with the conceptions of science that was configured at the end of the twentieth century, as scientific contribution to humanity. The accuracy of the concepts involved with these two terms is also subject to examination, analysis, reviews, and show several inaccuracies and controversies as part of the development problems of the Experimental Analysis of Behavior and the work of behavior analysts to develop new and relevant behaviors in society. These concepts are examined as part of the constitution of the concepts of "operant behavior," distinct from "response", "activity" or "contingency of reinforcement". The behavior as a system of interactions among classes of aspects of an environment, classes of activities of an organism and classes of subsequent environmental aspects of such activities is the object of examination of this text. Perhaps the concept of behavior is still more part of the problem than a solution in the context of working with this type of phenomenon.

Keywords: operant behavior, classes of responses, contingencies, contingencies of reinforcement, contingencies of three terms

Professor Titular (aposentado) dos Departamentos de Psicologia da Universidade Federal de Santa Catarina e da Universidade Federal de São Carlos. Bolsista-Pesquisador do CNPq.

Endereço para correspondência: Sílvio Paulo Botomé, spbot@terra.com.br 
"In the beginning there was the response..."

Donald Baer (1973)

"An operant is a class, of which a response is an instance or member..."

Skinner (1969)

Em 1927, Bertrand Russell publicou "An outline of Philosophy" (traduzido no Brasil, em 1969, com o nome de "Delineamentos da Filosofia"). Nesse livro, particularmente nos capítulos 1 e 2, o autor apresenta considerações a respeito do behaviorismo (watsoniano, no caso), destacando que, embora o mundo influencie a ação humana, há outra parcela, ignorada pelo behaviorismo a que o autor se referia: a influência (ou as alterações) que a ação humana produz no mundo. E o autor acrescentava, há também uma desconsideração de que esse mundo alterado (ou produzido) pela ação humana, por sua vez, influenciará a ação humana. Com esses textos, que Skinner, mais tarde, comentaria ter sido uma das fontes de informação que o auxiliaram no trabalho com a Psicologia, Russell estava indicando que estudar apenas uma parte da interação da ação humana com o mundo, como se o ambiente em que $\mathrm{o}$ ator exerce sua atuação fosse apenas um cenário inerte, era algo parcial. Apenas parte de uma unidade maior que, sem as outras partes, carecia de "sentido" ou seria "falsamente científico", uma vez que isolaria, como objeto de estudo, uma parte de algo que seria mais complexo para ser entendido. O exame - e a crítica! - era uma reação ao manifesto behaviorista (Watson, 1913). As considerações de Russell pareciam indicar que ele considerava o behaviorismo watsoniano incompleto. Ou, pelo menos, havia uma crítica ao que era considerado o objeto de estudo e de intervenção do qual se ocuparia - e definiria - a Psicologia tal como apresentado por Watson no que ficou conhecido como "Manifesto Behaviorista". Para Russell (1927/1969), o comportamento era mais do que uma reação a algum aspecto do ambiente.

Mas, muito antes de Watson (1913) e de Russell (1927/1969) oferecerem suas contribuições para o entendimento e delimitação do que poderia ser o objeto de estudo e de intervenção abrigado sob o nome de "Psicologia", o "fazer humano" ou a "atividade dos seres humanos" tinha sido objeto de preocupação. O mistério do "fazer" humano, durante muito tempo, envolveu não só seus determinantes como também suas características e a percepção desse processo. Desde o misticismo dos deuses determinando as características, até as "entidades internas", ainda persistentes no entendimento do que faz haver certas características no comportamento dos organismos, passando pelos espíritos malévolos, substâncias tóxicas até "doenças" diversas dos organismos como fonte desse fenômeno. Para a maioria das pessoas, e parte dos profissionais do comportamento, esse fenômeno permanece, em boa parte, algo misterioso. Tudo isso, porém, ocorreu ao longo de um extenso período da história do conhecimento em que não foram poucos os trabalhos e esforços para desenvolver um conhecimento a respeito do "misterioso fazer humano" com tantas variações e, ao mesmo tempo, com aspectos que se assemelham em muitos tipos de culturas, situações, pessoas e ações específicas.

Houve, no entanto, no começo do século $\mathrm{XX}$, algumas contribuições que possibilitaram uma mudança pronunciada na direção de estudo e de entendimento do comportamento humano e dos organismos vivos em geral. Watson e Russell, de certa forma, junto com outros pesquisadores, em várias áreas, que investigavam o mesmo fenômeno que estava no núcleo da proposição de Watson e na avaliação crítica de Russell, provocaram as bases para esforços específicos que criaram o que ficou posteriormente conhecido e difundido como "Análise Experimental do Comportamento". Um nome que indicava três processos: um como objeto de exame, outro como uma maneira de examinálo e um terceiro um procedimento para verificar e demonstrar sua ocorrência e características. O termo comportamento, porém, já existia antes e as contribuições da Ciência, posteriormente trouxeram contribuições que alteraram os referenciais a que esse termo pode fazer referência. As citações de Baer (1973) e Skinner (1969), como epígrafe deste texto, ilustram dois momentos em que o uso desses termos está sendo utilizado com referenciais diversos daqueles que havia antes das novas contribuições. Em que estágio o conceito de comportamento pode estar considerando o conhecimento que foi produzido até o início do século XXI? Como exemplo, no conhecimento contemporâneo, "resposta", "classe de respostas", "comportamento", "comportamento operante", "classe de comportamentos" são termos 
equivalentes ou seus referenciais são diferentes? E qual é o entendimento atual mais adequado para cada um desses termos coerentemente com o conhecimento disponível em relação ao anteriormente misterioso "fazer humano"? No que o conhecimento do comportamento dos organismos trouxe contribuições para entender melhor o que é esse tipo de evento?

\section{A CONTRIBUIÇÃO DA ANÁLISE EXPERIMENTAL DO COMPORTAMENTO PARA ENTENDER E LIDAR COM A ATIVIDADE HUMANA NO MUNDO}

É difícil entender e examinar o conhecimento e a tecnologia referentes ao comportamento humano sem considerar alguns aspectos que histórica, social, científica e metodologicamente têm caracterizado a área de conhecimento que está na sua origem: a Análise Experimental do Comportamento. Assim como é difícil examinar os processos que são alvos de trabalho nos campos de atuação profissional em que esse conhecimento é, de alguma forma, utilizado, sem alguns cuidados ou procedimentos que, com o desenvolvimento dessa área, foi possível elaborar. Conceitos fundamentais, descobertas básicas, campos de atuação nos quais têm sido utilizadas essas descobertas e esses conceitos, metodologia de pesquisa básica e de avaliação das intervenções, problemas já equacionados ou pelo menos percebidos (conceituais ou tecnológicos), a tecnologia já existente e em utilização e o exame dos efeitos sociais dos trabalhos com o conhecimento dessa área têm sofrido transformações. E, além disso, têm exigido uma sistematização cada vez maior do volume e da articulação de informações de diferentes épocas, autores, tipos de problemas ou de trabalho e de discursos nem sempre afinados com uma terminologia que seria coerente com as descobertas da área de conhecimento e dos múltiplos campos de atuação em relação ao comportamento dos organismos. Parece haver um trabalho imenso já feito e outro, talvez maior ainda, por fazer em relação à contribuição da Análise Experimental do Comportamento quanto às relações do "fazer humano" com o mundo no qual tal "fazer" é realizado.

No âmbito da área que recebeu o nome de "Análise Experimental do Comportamento" foi produzida uma razoável quantidade de contribuições em relação ao conhecimento a respeito do comportamento dos organismos. Como conhecimento, como maneira de trabalhar e como conjunto de dados, os que trabalharam com a Análise Experimental do Comportamento construíram contribuições desde o conceito de comportamento até os processos e sua dinâmica envolvidos nas interações específicas que constituem esse fenômeno e dele com outras variáveis que, de alguma forma, o influenciam ou dele decorrem em diferentes períodos de tempo e distâncias no espaço. A pesquisa, de qualquer tipo, a sistematização do conhecimento e sua utilização em trabalhos em diferentes campos de atuação são ainda uma enormidade de informações a serem continuamente examinadas, avaliadas, aperfeiçoadas e, com isso, poder manter a continuidade do desenvolvimento da área que recebe esse nome. O comportamento (como categoria ampla de fenômeno) tem sido cada vez mais examinado em tipos, em extensão e em profundidade. Tais exames têm propiciado cada vez mais dados e possibilitado elaboração de novos conceitos ou aperfeiçoamento e reformulação dos já existentes. A experimentação e a avaliação cuidadosas têm cada vez mais consolidado as verificações e demonstrações das relações entre as variáveis envolvidas nesse tipo de fenômeno.

As próprias revistas e publicações, de certa forma, são uma evidência da participação da Análise Experimental do Comportamento no desenvolvimento dessa área de conhecimento. Do início da pesquisa básica (marcada historicamente pela criação do Journal of the Experimental Analysis of Behavior) até o uso do conhecimento produzido por esse tipo de pesquisa (também marcado inicialmente pela publicação do Journal of Applied Behavior Analysis) e a crítica e discussão do próprio trabalho, procedimentos, conceitos, sistematização e pressupostos (iniciado mais formalmente como parte integrante da área, pelo periódico Behaviorism) houve um incremento de trabalhos e publicações muito grande envolvendo dezenas de periódicos e milhares de pesquisas distribuídos em vários países do mundo. Entre os quais, e talvez marcadamente, o Brasil. Essa história de trabalho significa a existência de um tipo de contribuição - talvez grandemente desconhecido ainda - para a Psicologia, tanto como área de conhecimento, particularmente as contribuições científicas e filosóficas, quanto como campo de atuação profissional para psicólogos, em muitas 
modalidades de trabalho. Dificuldades, controvérsias e problemas ainda não resolvidos e possibilidades da Análise Experimental do Comportamento também são uma evidência de sua contribuição: colocar problemas e exigir o constante alerta para uma investigação mais cuidadosa, mais exigente, mais demonstrativa e, mesmo, mais difícil em relação ao seu objeto de estudo e ao conhecimento produzido. Com as mesmas exigências para o trabalho nos campos de atuação em que esse tipo de conhecimento é utilizado.

Seria possível examinar e avaliar as múltiplas contribuições em diferentes sub-áreas de estudo do comportamento (conforme os objetos ou processos de estudo) ou nos variados campos de atuação em que esse conhecimento é utilizado e também produzido, inclusive em vários tipos de testes ou verificações profissionais (terapia, educação, organizações sociais, processos de trabalho, planejamento de ambientes etc.), ou também, nos vários tipos de conhecimento que são produzidos (teoria, tecnologia, sistematização, avaliação, crítica, informações básicas etc.) como contribuição dessa área. Para os propósitos deste trabalho, porém, interessam apenas alguns aspectos. Esses, de certa forma, estão reunidos por um denominador comum: não são patrimônio exclusivo da Análise do Comportamento, nem apenas fruto do trabalho dos analistas do comportamento. A Análise Experimental do Comportamento emprestoulhes a força dos dados obtidos por meio de cuidadosa e extensa verificação experimental. Uma ampla gama de afirmações e controvérsias a respeito do comportamento, particularmente o humano, saíram da esfera da especulação, de qualquer tipo, ou da reflexão filosófica (mesmo a mais cuidadosa e bem elaborada) e passaram pelo crivo da verificação por meio da experimentação, tornando-se objeto de investigações e demonstrações sistemáticas. Possibilitando, também, a extensão dessa experimentação para a intervenção com diferentes procedimentos que constituíram, ao longo do tempo, uma tecnologia básica para trabalhar com o comportamento.

Há, também, outra perspectiva de avaliação diferente daquela que valoriza e integra o conhecimento científico continuamente: o conhecimento que desmistifica as crenças a respeito do comportamento tem sido temido e evitado. Para muitos profissionais, aí incluídos estudiosos de diferentes áreas e variadas formas de conhecer, há uma tendência em negar, recusar, evitar ou impedir conhecimento que questione ou ponha em dúvida crenças e conhecimentos pessoais já existentes. Ou que ponha em risco as preferências de cada um ou daquilo que utiliza para viver e trabalhar com segurança e ganhos pessoais no ambiente em que realiza suas próprias atividades. O que também precisa ser considerado no exame do entendimento dos conceitos existentes.

Uma área em que o conceito de comportamento dos organismos vivos e grande parte das variáveis que interferem com sua ocorrência ficaram cientificamente conhecidos, mesmo que ainda desconhecidos ou inacessíveis para grande parte da sociedade, é o que ficou denominado por Análise Experimental do Comportamento, identificada por alguns como parte da filosofia correspondente a essa área, com o nome de "behaviorismo" (ou "comportamentalismo"). A área tem sido construída por esforços de muitos estudiosos para lidar melhor com o conhecimento e com o trabalho profissional em relação ao comportamento dos organismos. Muito embora, nesse tipo de trabalho, haja quase sempre uma confusa mistura - com ingredientes difusos - de muitos tipos de concepções, teorias, definições e sistemas de referência, dificultando um desenvolvimento contínuo e articulado. Por exemplo, quantos que trabalham com o conceito de comportamento dos organismos vivos fazem distinção precisa entre "behaviorismo metodológico" e "behaviorismo radical", identificando as decorrências dessas duas perspectivas, além de algumas diferenciações superficiais? Menos profissionais ainda tem claro que o desenvolvimento do conceito de comportamento operante após as contribuições que Skinner e seus colaboradores, ao longo de décadas, criaram, junto com o conceito de contingências de reforçamento, um "ponto de mutação" (utilizando a controvertida analogia de Capra, 1992) quanto ao conceito de "fenômeno psicológico" na história do conhecimento.

Mesmo com as dificuldades e as limitações de inserção desse conhecimento e da tecnologia decorrente dele na sociedade, houve, no decorrer do século XX, um grande desenvolvimento na delimitação, ou no esclarecimento, de suas características e determinantes. As transformações do conceito de comportamento, desde as contribuições 
no estudo do comportamento reflexo até as mais recentes descobertas e construções conceituais a respeito do comportamento operante são uma das, talvez, mais importantes elaborações, apesar das controvérsias existentes, quanto àquilo de que se ocupa a Psicologia como área de conhecimento e como campo de atuação profissional.

\section{O DESENVOLVIMENTO DO CONCEITO DE COMPORTAMENTO HUMANO NO ÂMBITO DA ANÁLISE DO COMPORTAMENTO}

Nos anos mais recentes, Todorov $(1989,2002)$, por exemplo, examinou a Psicologia como estudo de interações, explicitando algumas contribuições para o entendimento do conceito de comportamento em suas possíveis transformações em trabalhos de diferentes pesquisadores na área da Análise do Comportamento. Sério $(1983,1990)$ destacou o exame do conceito de "classe de respostas" em sua formulação inicial e as relações entre comportamento reflexo e operante, acentuando a importância desses conceitos no entendimento do que significou o conceito de "comportamento" com as contribuições de Skinner. Sério mostrou quanto Skinner (1935) foi além de uma concepção genérica de "estímulo" e "resposta" para outra concepção, mais adequada funcionalmente ao que constituía o montante de descobertas a respeito das interações entre ambiente e atividade de um organismo vivo.

Tais autores mostram haver distância de concepções mais atuais em relação ao que, até a elaboração do conceito de "operante", era entendido pelo conceito "comportamento". Em 1980, Botomé apresentou em "prefácio" de um trabalho (tese de doutorado), no qual também reviu a contribuição, mais antiga, de autores similares aos indicados por Todorov e Sério e sistematizou, após essa apresentação, algumas implicações do conceito de comportamento como "interação entre características das respostas de uma classe, características de classes de aspectos do ambiente antecedente e características de classes de aspectos do ambiente subsequente ou decorrente dessas respostas" (Botomé, 1980). Embora em tempos diferentes, os trabalhos tiveram por objetivo contribuir para a formulação e distinções entre o conceito de comportamento desenvolvido no âmbito das contribuições da Análise Experimental do Comportamento e outras concepções que estavam disseminadas até a época em que tais trabalhos foram realizados. Algumas dessas concepções ainda restritas ao entendimento watsoniano ou pavloviano de comportamento, por exemplo, o que é considerado na obra de Merleau-Ponty (1972/1975) e na crítica de Russell (1927/1969). Comparando as contribuições a respeito da avaliação do conceito de comportamento operante desde a proposição de Skinner com o que é utilizado como conceito de comportamento, mesmo nas publicações da área, o conceito parece permanecer com problemas em sua delimitação para muitos dos que o utilizam, ainda no começo do século XXI.

Observando apenas a diferença entre o que Skinner considerava "comportamento" em 1938 e no que ele apresenta em 1969 há uma distinção que ilustra um enorme trabalho realizado. Neste, encontram-se muitos dados sendo progressivamente acumulados e esclarecendo cada vez mais o conceito de comportamento. Em 1938, Skinner afirmava que "o comportamento era uma parte da atividade total de um organismo e que (...) behavior is what an organism is doing..." (Skinner, 1938, p. 6). Em 1969, o mesmo autor salienta o papel das complexas interações entre as classes de estímulos antecedentes, classes de respostas e classes de estímulos consequentes às respostas dessas classes para ser possível entender o comportamento que ele adjetivou como "operante" para destacar a interação com o que se seguia às classes de respostas, em distinção com o que era conhecido, antes, como "comportamento reflexo", uma interação entre as classes de respostas com o que as "antecedia". O termo "operante", mesmo quando não explícito, vai ser o "tipo" de comportamento (não mais em um sentido genérico) a que vai ser feita referência no âmbito das contribuições e entendimento da Análise do Comportamento. Por isso, inclusive, a diferença entre "análise do comportamento" (operante, no caso) e "análise de comportamentos" que pode referirse, inclusive a comportamento no sentido genérico do termo em qualquer área de conhecimento ou em muitos sentidos no âmbito da Psicologia e a qualquer tipo de "atividade", mesmo a de seres inanimados que se transformam por ação do ambiente (desgaste de materiais, interações entre substâncias quando em contato, mudanças climáticas em função de interações entre condições ambientais etc.).

O termo "operante", acrescido por Skinner 
para referir-se ao comportamento dos organismos vivos, foi mais que um adjetivo. Ele representou a síntese de uma descoberta que alterou o que era entendido pelo termo "comportamento". E atendeu a críticas como a formulada por Russell (1927/1969) em relação às proposições do "behaviorismo watsoniano": o comportamento não se reduzia a respostas a estímulos, mas era também uma operação de transformação que o organismo produzia em seu ambiente ("mundo", nos termos de Russell, em 1927). Na direção de esclarecer os dois conceitos, De Rose (1997) apresentou, em um texto didático, as diferenças entre "reações reflexas" e "comportamento operante", embora ambos possam combinar-se ou ser misturados e as propriedades aparente de dois tipos de comportamento possam ocorrer conjuntamente ou como parte de uma mesma unidade. O conceito de "unidade de comportamento" também é indicado como problema pelo autor. O termo "operante" representou a síntese de descobertas que alteraram o que, até então, era entendido como "comportamento". Com o termo "operante", Skinner inclui a noção de que o que um organismo "fazia" era uma operação de mudança em relação a seu ambiente (e este último termo era um conceito mais esclarecedor a respeito do que, para muitos, era a "realidade" ou o "mundo" até então). O próprio conceito de "fazer" ("behavior is what an organism is doing"), na concepção de comportamento operante, trazia consigo a decorrência (ou exigência conceitual) de haver alguma alteração no "ambiente" em que o organismo estivesse "doing”. Essa decorrência, por sua vez, acarretava outra: o conceito de ambiente já não era apenas o que existia (antes do organismo atuar), mas também o que passava a existir pela ação do organismo ou após sua ocorrência. Tais descobertas e conceituações decorrentes não eram apenas promissoras, eram provocadoras de transformações muito grandes e inesperadas no âmbito do que era entendido como objeto de estudo e de trabalho em Psicologia. Não é de estranhar que até o começo de um novo século elas ainda estejam sem ser plenamente conhecidas e entendidas. A percepção de seu potencial inovador exige juntar muitas "peças de um quebra-cabeças" sem um modelo a priori como orientação do que fazer com as "peças". O que obriga a construir algo novo a partir de partes que foram sendo descobertas em relação a um processo precedido de grande quantidade de conhecimento, nem sempre adequado, mas apoiado em muitos anos de uso e até mesmo de condescendência com sua utilização indiscriminada e de forma confusa.

De 1938 a 1969, vários cientistas examinaram múltiplos problemas relacionados às proposições de Skinner. O que continuou a ser feito em relação ao comportamento com contribuições variadas em relação a como entender ou formular seu conceito. As ênfases nas definições mudaram nesse período e continuaram a ter variações de entendimento e formulação nas décadas seguintes, avançando pelas duas primeiras décadas do século XXI. Skinner, porém, em 1931, já apresentava uma contribuição que, até o final da década de 1970, ainda não havia sido suficientemente esclarecida pelo menos para obter algum consenso, ou consideração extensiva, na literatura que foi produzida nos anos seguintes (Botomé, 1980, 2001). Em 1931, porém, ao examinar o conceito de comportamento reflexo, Skinner já havia proposto uma definição em termos de "correlação entre estímulo e resposta". O reflexo deixava de ser considerado a resposta ( $R$ ) ou a atividade do organismo, mesmo diante de um estímulo, para ser considerado uma relação específica entre um estímulo e uma resposta.

Em 1934, Pavlov considerou "legítimo chamar de reflexo absoluto a relação permanente entre o agente externo (S) e a atividade (R) do organismo por ele determinada, e de reflexo condicionado a relação temporária" (Pavlov, 1934/1979, p. 42). A unidade de análise, portanto não era a atividade (ação ou "resposta") do organismo, mas o reflexo, entendido como relação entre um agente externo (antecedente) e a ação do organismo. O "estímulo" e a "resposta" eram apenas dois componentes usados para identificar a interação existente, por meio da análise: identificação dos componentes, e decorrente caracterização (e nomeação) dessa relação.

Em 1935, Skinner acrescentou mais um aspecto ao conhecimento desse conceito, considerando que os estímulos e respostas variam de um instante para outro e isso faz com que o reflexo não possa ser definido em termos da interação de um estímulo particular e uma resposta particular. Reflexos eram, então, considerados como interações entre classes de respostas e classes de estímulos (Skinner, 1935). Como classe, o autor entendia todos os eventos ou 
todos os graus das variáveis que pudessem definir ou fazer existir a interação (o que constituía a exigência de uma definição funcional e não pelas características formais dos eventos). Com isso, foram colocados em evidência os critérios para escolher unidades desse tipo de comportamento e unidades dos componentes dele. Tais componentes da unidade denominada "comportamento reflexo" seriam classes de respostas e classes de estímulos. O conceito de "classe", embora parecesse simples, iria ser crucial para entender o processo relacionado ao nome "comportamento" nos anos seguintes, quando o próprio Skinner acrescentaria a isso alguns componentes que tornariam mais complexa (e mais clara e completa) a interação que estava em exame. Sério (1983, 1990) examina o conceito de "classe", para referirse a "estímulos" e "respostas", de forma extensa e detalhada, com avaliações de suas decorrências para o desenvolvimento quanto ao conhecimento do comportamento.

A partir de 1938, Skinner descobriu e construiu, para a Psicologia, o conceito de "comportamento operante", enfatizando outra interação que não mais aquela que caracterizava o comportamento reflexo. No "comportamento operante", a relação relevante está entre a atividade do organismo e o que se segue no ambiente logo após essa atividade ou, integrando o conceito já examinado por Skinner em 1935, "classe de respostas" e "estímulos de uma classe" que se seguem às "respostas de uma classe". O exame de Skinner ao comportamento reflexo em 1931 e 1935 era extensivo ao novo aspecto das atividades dos organismos vivos que ele evidenciou com seu trabalho de análise e de demonstração por meio de verificação experimental. Isso acarretou decorrências para o conceito de comportamento e para o entendimento da determinação desse fenômeno.

Seria o "comportamento operante" caracterizado por Skinner outra modalidade de comportamento ou outra parte do conceito de comportamento como uma unidade maior do que aquela que Pavlov havia evidenciado com suas investigações? E, se for o caso, será sempre assim? $\mathrm{Ou}$, sendo, como ocorre a interação entre as duas partes? A partir dos trabalhos de Skinner em 1931, 1935 e 1938 surgiram vários outros, investigando o conceito de comportamento e seus usos e esclarecendo vários aspectos relativos a tal conceito.
Mesmo assim, esses trabalhos, muitas vezes não consideraram suficientemente as contribuições que, acumuladas e articuladas, levaram ao entendimento de comportamento, no âmbito da Psicologia, como uma específica e complexa interação do organismo com um ambiente que existe quando o organismo apresenta sua atividade e com um ambiente que ocorre depois dessa atividade ser realizada. Desde 1938, com o Behavior of Organisms, Skinner examina, com vários colaboradores, essas interações, embora não pareça ter esclarecido o suficiente para que fosse mais evidente, para muitos psicólogos, a profunda transformação conceitual que tais contribuições acarretaram para a Psicologia. Elas, porém, constituíram os referenciais para o desenvolvimento da Análise Experimental do Comportamento (agora, integrando o conceito de "operante"), como conhecimento científico desse fenômeno, e marcaram da mesma forma o aperfeiçoamento de seu uso nas intervenções profissionais (Baer, 1973; Barlow \& Hersen, 1984; Barlow \& col, 1986; Castro, 1975; Daniels, 1989). Skinner viabilizava, no âmbito do trabalho científico, respostas às indagações, críticas e contribuições de Russell (1969), feitas em 1927 no âmbito da Filosofia. Vários outros cientistas e profissionais aumentaram essa viabilidade com múltiplas contribuições, acarretando uma grande quantidade de usos e novas verificações e demonstrações das descobertas feitas e dos conceitos formulados para denominar tais descobertas.

Staddon (1969) retomou e examinou o conceito de comportamento operante, salientando vários problemas envolvidos como conceito: oque defineuma classe de respostas? E uma unidade comportamental? $\mathrm{E}$ as interações entre essas "respostas" e os aspectos dos ambientes antecedente e subsequente às classes que as reúne? Fundamentalmente, Staddon provocava o prosseguimento do exame do conceito de comportamento operante, colocando em destaque explícito seis expressões a esclarecer e articular no conceito: comportamento (talvez também algum tipo de articulação entre "reflexo" e “operante"?), estímulo, resposta (e suas unidades), classes de estímulos (antecedentes e subsequentes às respostas dos organismos), classes de respostas e comportamento operante. Os aspectos considerados por Staddon pareciam esclarecimentos importantes para estabelecer bem o que representava a 
contribuição do conceito de comportamento operante para o desenvolvimento da Psicologia.

Schick (1971) indicou ainda outros problemas em relação ao conceito de comportamento: quais critérios para denominar ou definir uma classe de respostas? O autor estudou um conjunto de trabalhos de Skinner, publicados entre 1932 e 1969, examinando o conceito de operante e os critérios usados ou propostos para definir esse conceito. Schick criticou a dependência do conceito de comportamento operante ao de contingência de reforçamento, salientando a diferença entre eventos que se seguem a uma classe de respostas e eventos que são produzidos por uma classe de respostas. O autor ainda examinou a afirmação que o "reforço" (ou o "evento que se segue à resposta"?) não é contíguo a uma classe de respostas, mas contíguo a propriedades das respostas de uma classe. Schick questionou qual seria a propriedade crítica, pondo em dúvida que seja a forma (ou "topografia") da "resposta". Ele ainda ressaltou que o "efeito" (de uma atividade) parece ser crítico para definir um comportamento e não para definir uma resposta (ou uma classe), questionando o que seja considerado "efeito" em relação ao comportamento: o que é produzido ou o que se segue a uma determinada propriedade de uma classe de atividades? As diferenças entre "evento que se segue", subsequência, contiguidade, consequência ou decorrência (no sentido de maior variação do tempo de ocorrência do evento subsequente em relação à realização da atividade de uma classe) eram novas exigências de esclarecimento para a terminologia e para a identificação do comportamento (sempre operante) que ocorresse e do que era importante para defini-lo, delimitá-lo ou intervir em sua ocorrência.

Schick considerou que tais esclarecimentos são, particularmente, importantes em relação à compreensão do comportamento supersticioso. Se o "efeito de uma resposta" for considerado o que é produzido (e não o que apenas se segue) pelas respostas de uma classe, como ficariam os limites entre comportamento supersticioso e comportamento operante? Como seria a articulação desses dois conceitos? Se tivessem a mesma função, o conceito de comportamento supersticioso perderia o sentido? Os dados de pesquisa disponíveis mostravam o contrário. No caso do comportamento supersticioso, o que apenas segue às atividades de uma classe tem um efeito importante: "funciona como se fosse produzido" pelas atividades do organismo. Isso o torna um operante igual ao que tem as subsequências efetivamente produzidas pela ação do organismo? As implicações desse questionamento são importantes para identificar e nomear um comportamento e cada um dos três de seus componentes e, se não adequadamente examinadas e resolvidas no âmbito da grande quantidade de outros conceitos envolvidos no conceito de comportamento, poderão comprometer o desenvolvimento do conhecimento a respeito do "operante".

Schick (1971) ainda afirmou que há implicações dessas mesmas questões para os conceitos de extinção e generalização, se for considerado no conceito de comportamento operante somente "as propriedades das respostas de uma classe que produzem um efeito" (em oposição às atividades que apenas se seguem a determinados eventos). Os dois conceitos, fundamentais para o desenvolvimento de novos comportamentos, são estreitamente dependentes da diferença entre "ser produzido pelas respostas de um organismo" e "apenas seguir-se às respostas de um organismo". Principalmente no âmbito da construção (profissional?) de comportamentos relevantes para a vida e para a sociedade, como é o caso do ensino, da terapia, do treinamento, da definição de atribuições e competências de cargos e funções em organizações etc. Para esse mesmo autor, a definição de comportamento operante deve, fundamentalmente, referir-se à relação entre certas propriedades das respostas do organismo no ambiente e o que efetivamente é produzido por elas nesse ambiente (ou ser "efeito" das mesmas) e não a quaisquer outras propriedades dessas mesmas classes de respostas. A controvérsia examinada por Schick deixou um problema que constituiu mais uma contribuição no desenvolvimento do conceito de comportamento operante: o que exatamente constitui a interação do ponto de vista do que se segue à resposta para identificar o que está sendo feito pelo organismo? Isso pode não aparecer como problema em alguns casos (como "segurar um lápis"), mas pode não ser nada simples como, por exemplo, "vacinar uma pessoa contra uma doença". Que "resultados", neste caso, constituirão o que definirá que alguém foi vacinado por meio da ação de outra pessoa? Ou o resultado do que acontece na resistência desse organismo contra a doença de interesse não 
importa? Se importar, e o resultado for resistência desse organismo à doença para a qual foi "vacinado", os eventos imediatos apenas ajudam a denominar classes de comportamentos mais moleculares (na linguagem de Baum, 2004 e 2012 e Simonassi e col., 2012) e não componentes do comportamento relevante (mais molar) ou mais abrangente e com possibilidade de serem decompostos e identificados com clareza em todos os comportamentos que a classe abranger ou analisados em componentes que não tem uma interação imediata no tempo ou próxima no espaço. Sem esses esclarecimentos haverá o risco de, no exemplo citado no campo da saúde, ocorrerem muitos comportamentos que serão reduzidos a rituais de injetar substâncias no corpo das pessoas, não importando outros resultados que não "algo injetado" e talvez alguns outros "efeitos" secundários definidores de outras "interações das atividades com o meio subsequente a elas: alguma dor para quem for vacinado, a aprovação de algum "chefe", o registro de uma atividade realizada, o pagamento obtido por fazer isso, a correspondência entre atividades realizadas e regras para fazê-las - uma espécie de comportamento "ecóico", ou de imitação, ou de "despachante burocrático" - e outros exemplos que poderiam ser identificados. As controvérsias destacadas pelo exame de Schick podem ser maiores e mais importantes do que pareceram à primeira vista ou na época.

No exame feito por Schick (1971) também foram identificados problemas em relação às diferenças entre "classes de respostas" e "cadeias de respostas". Ambas igualmente podem ser consideradas como uma unidade de "comportamento operante"? Independentemente de sua amplitude? "Fazer uma pesquisa científica" é apenas uma ampla classe de respostas? Ou é uma classe abrangente de comportamentos? Ou uma longa sequência de respostas? Ou uma complexa cadeia de comportamentos? Ou é um sistema de múltiplas cadeias de comportamentos que podem combinarse de diferentes formas? O termo (e conceito) correto é "cadeia de respostas" ou "cadeia de comportamentos"? O que exatamente é "encadeado" (ou apenas "sequenciado")? Em qualquer caso, por exemplo, quais são as classes de comportamentos básicos que constituem a classe geral que costuma ser denominada por "pesquisar cientificamente"?
Ou tal "atividade" não é comportamento? Se o que define um comportamento é o seu efetivo resultado no ambiente, quando é adequado utilizar essas denominações? As perguntas, provocadas pelo exame de Schick, parecem pertinentes: elas exigem a explicitação de critérios muito específicos e envolvem vários conceitos para definir o que é, enfim, o comportamento operante em qualquer dos casos que os exemplos e questionamentos ilustram como potenciais aspectos a esclarecer.

$\mathrm{O}$ mesmo autor ainda considerou que, ao fazer experimentos em Psicologia, os pesquisadores definem uma propriedade qualquer de uma classe de respostas em relação à qual se seguirá um evento (que aparecerá como consequência das respostas com as propriedades definidas). A "consequência", por sua vez, é escolhida e planejada por quem faz a pesquisa. Isso não é problema para demonstrar os efeitos dos eventos que se seguem às atividades de uma classe apresentadas por um organismo. Mas, ao trabalhar com o comportamento humano, em ambientes "naturais", certos resultados (ou alterações do ambiente) só podem ser obtidos por respostas dos organismos, de certas classes e com propriedades específicas (variáveis e graus dessas variáveis) e não por outras, principalmente quando arbitrariamente definidas por alguém. Por essas razões, as propriedades relevantes das "respostas" e dos ambientes que irão compor a relação denominada "comportamento operante" precisam ser descobertas (o que inclui sua verificação e demonstração) e não apenas indicadas ou delimitadas por alguém. Tais questões, de uma perspectiva mais ampla, são objeto dos exames de Baum $(2004,2012)$ e de Simonassi e col. (2012), referindo-se a concepções (ou percepções e referências) moleculares ou molares do comportamento ou das interações em exame quando se investiga ou desenvolve comportamentos em qualquer modalidade de trabalho desses tipos. Ribes é outro autor que problematiza diretamente o objeto de estudo da Psicologia (Ribes, 1989, 2000, por exemplo) ou de sua aplicação (2009), acarretando múltiplas exigências de exame no próprio conceito de "comportamento" e sua utilização em "aplicações" profissionais, problematizando o conceito de "aplicação" do conhecimento produzido no âmbito da Análise Experimental do Comportamento.

O exame de Schick (1971) não foi uma crítica ou desconsideração aos experimentos de pesquisa 
básica no laboratório. Nem sequer colocou em dúvida a importância do que se segue às atividades de um organismo para identificar e nomear a interação que tais atividades do organismo estão estabelecendo com o ambiente. Ele estava apenas identificando problemas que precisam ser resolvidos para que o conceito de comportamento operante, investigado, descoberto e caracterizado pela pesquisa em Análise Experimental do Comportamento, possa ser suficientemente completo, claro e preciso para abranger toda a gama do fenômeno denominado "comportamento" dos organismos vivos, no âmbito da Psicologia. Qual a unidade de cada ocorrência de comportamento? $\mathrm{Ou}$, integrando o conceito de "classe": de cada ocorrência de comportamentos de uma classe? Como fica a outra parte da relação com o ambiente (aquele que existe antes ou quando a "resposta" do organismo é apresentada) na sua relação com o conceito de "operante"? Ela não precisa ser considerada? De que forma o seria para entender todo o conjunto como uma "unidade comportamental"? Ou, o que exatamente representa cada um dos componentes (os aspectos do ambiente, as propriedades da atividade e as propriedades do ambiente resultante de sua apresentação) no conjunto denominado de "comportamento operante"? Ou o conjunto deles, em interação, não constitui uma unidade passível de análise (de identificação das partes componentes) e com a necessidade de verificação e demonstração de que efetivamente são componentes de uma unidade? Isso tudo parece estar no núcleo do trabalho de Análise Experimental do Comportamento desde sua gênese.

Alguns dos problemas destacados por esses autores já aparecem no livro "Verbal Behavior", no qual Skinner (1957) usou o critério de "efeito a obter" para nomear categorias de comportamento verbal (tato, mando, ecóico etc.). Essas denominações ("categorizações") poderiam ficar comprometidas se o critério adotado fosse "efeitos que se seguem à resposta". Por exemplo, alguém pedir água a outra pessoa e haver um resultado diferente de esta pessoa oferecer a água solicitada. Uma explicação do interlocutor de que a água não é boa para beber, uma recusa em atender o pedido, a pessoa jogar a água em quem a solicitou etc. Qualquer dessas "respostas" tornaria a verbalização inicial algo diferente de um "mando"? Em qualquer dos exemplos, a interação entre atividade verbal e consequência dessa atividade é diferente de "pedir água e, por 'causa' disso, receber água para beber". Somente em determinadas circunstâncias ou contingências, tais consequências poderiam acontecer e não seriam "produzidas" (literalmente) ou "causadas" pela verbalização do "pedinte" e ocorressem mais provavelmente em função, pelo menos também, de outras circunstâncias existentes e relativas ao comportamento de quem se comporta dessas formas diante do que é solicitado pelo "falante". O que definiria então, qual é o comportamento do "falante" ao "pedir água" em tais circunstâncias? A caracterização de um operante parece exigir um exame mais complexo do que três conjuntos de aspectos identificados por relações temporais ou espaciais. Talvez existam mais variáveis envolvidas nessa interação.

Em outro caso, ainda como exemplo: como denominar um comportamento pela expressão "limpar uma mesa" (onde não há sinais de sujeira) simplesmente por ver a pessoa esfregar a mesa com um pano úmido? Ou, havendo sinais de sujeira na mesa, a pessoa passar repetidamente o pano úmido e não remover a sujeira existente? Quando tal comportamento poderia ser denominado de "limpar"? Que aspectos precisam ser observados e identificados para poder nomear tal comportamento com a segurança de que está sendo verificada a ocorrência de uma unidade de comportamento operante, mesmo que a abrangência da classe a que pertence possa variar? As múltiplas interações entre atividades do organismo (atividades da mesma classe) podem constituir comportamentos diversos se os aspectos do ambiente variarem? Que conceitos ainda seriam necessários existir ou ser mais precisamente delimitados para o entendimento do que é o comportamento, depois do surgimento do conceito "operante", descoberto e proposto - como denominação - para tal tipo de interação entre as características da atividade do organismo e determinados aspectos do ambiente? E se o organismo, ao esfregar a mesa, estiver produzindo sensações em seu corpo como "resultado" dessa atividade (como quando alisa o cabelo ou acaricia o próprio corpo, por exemplo), como seria denominado esse comportamento?

Os exames de Schick, Baum e Ribes ainda são fortalecidos e enriquecidos com a consideração de outros aspectos nos artigos de Bolles (1970) e 
de Seligman (1970). Bolles examinou as diferenças entre as reações específicas das espécies e as relações arbitrárias estabelecidas, nas pesquisas de laboratório, entre classes de estímulos antecedentes, respostas selecionadas e consequências apresentadas pelos pesquisadores. Seligman acrescentou a esses problemas os conceitos de preparação, não preparação e contra-preparação do organismo para responder a certos tipos de estímulos ou perceber as relações entre aspectos das situações antecedentes, as propriedades das ações e os aspectos das situações consequentes ou subsequentes em relação a essas propriedades das ações apresentadas pelo organismo. Talvez o que se aproxima do que, mais tarde, vai ser enfatizado como condições - e operações - estabelecedoras para a ocorrência de uma interação específica (?). Tais autores também não estavam pondo em dúvida as relações entre os três componentes do comportamento, de acordo com as contribuições da Análise Experimental do Comportamento e sua importância para entender os processos psicológicos. Eles estavam problematizando no que está apoiado o conceito de comportamento dos organismos vivos, identificando aspectos específicos importantes para haver generalização do conceito para outras situações. E para haver discriminações adequadas entre os componentes de um comportamento, entre as interações estabelecidas em cada caso e problemas relativos aos conceitos de classes (de estímulos, de atividades - respostas? - ou de comportamentos), entre as variações de amplitude das classes de comportamentos e as relações entre classes e cadeias de comportamentos e entre as variedades de eventos que podem acontecer tanto como antecedentes como consequentes de "respostas de uma classe" de um organismo.

Esses autores destacaram que a escolha de variáveis e a manipulação controlada em laboratório têm, em si, o problema das diferenças entre consequências naturais e consequências arbitrárias, não deixando clara a diferença entre eventos que se seguem e eventos efetivamente produzidos pelas ações ou atividades dos organismos. Destaque-se que os estudos de laboratório com comportamento supersticioso respondem ao problema dos eventos que se seguem sem relação funcional com as "respostas", mas não auxiliam a esclarecer o conceito de comportamento operante como uma interação especial ou específica entre os três componentes dessa interação. Permanece a pergunta: quais eventos componentes de uma interação entre atividades de um organismo e seu ambiente são importantes para delimitar qual especificamente está sendo o comportamento desse organismo?

Ainda quanto ao exame de problemas relacionados ao conceito de comportamento operante, Catania (1973) explicitou o que considerava fundamental para definir o conceito. $\mathrm{O}$ autor fez considerações a partir da afirmação de Skinner (1969) quanto a ser sempre sobre propriedades das respostas de uma classe que um dado evento se segue (é contíguo no tempo e no espaço) e que é essa relação que define o "operante". Apareceu, neste caso, o termo "contingente" com o sentido de "contíguo" (junto a) e não no sentido de ser circunstancial e não necessário como significa o conceito de "contingência", coerentemente com o termo "evento" (de "eventual" e não "obrigatório" ou "constante"). Isso exige um exame do conceito de "contingência" e de "contingência de reforçamento" como dois outros conceitos marcantes para a mudança no entendimento dos processos psicológicos a partir dos conceitos de "comportamento operante" e "contingência de reforçamento" (ver, por exemplo, em Todorov - 1989 - e Souza-2000, um exame dos conceitos de "tríplice contingência" e de "contingência de reforçamento") que continuaram ou ampliaram seu trabalho, o que inclui o minucioso exame de Lewin (1935/1975) em relação às concepções aristotélicas e galilêicas na Psicologia "contemporânea" (em 1935). Talvez, ainda não tenha havido um suficiente entendimento das exigências de elaboração dos conceitos da Análise do Comportamento em relação a essas duas concepções.

Para Skinner (conforme Catania, 1973), o que define um operante é um conjunto de circunstâncias (contingências) específicas (em interação?), o que salienta os problemas existentes no uso indiscriminado dos termos "resposta" (ou ação, ou atividade?) ou "classe de respostas" como sinônimos de comportamento operante. Para Catania, o conceito de comportamento operante deve basear-se em uma ênfase nas propriedades das interações entre "respostas de uma classe" e "estímulos de uma classe" (antecedentes e subsequentes ou consequentes) e não apenas nas propriedades das "respostas de uma classe". Como no conceito de comportamento 
reflexo, examinado por Skinner (1931) e Pavlov, em 1934, o aspecto crítico no conceito de comportamento operante é uma interação (ou um sistema delas?) entre propriedades de eventos ambientais de uma classe e propriedades das atividades de uma classe de atividades apresentadas por um organismo, integrando o conceito de "classe", proposto por Skinner (1935). Catania não deixou claro que o aspecto crítico, como ele destacou, envolva a noção de "classes de eventos", uma vez que, conforme o exame de Skinner (1935), não se trata de eventos particulares, mas de tipos (conjuntos, classes) de eventos que se repetem com a mesma funcionalidade embora variem em alguma característica ou grau de qualquer característica que apresentem. A noção de circunstância ou "contingência" (Skinner, 1969) será também uma parte importante do conceito. Noção, aliás, já presente no conceito de "classe" (que se define por uma "interação funcional" e não por características formais e "necessárias" ou "propriedades essenciais"), sem ainda considerar a especificidade do conceito de "contingência de reforçamento" que traz novos aspectos, também marcantes, para o entendimento dos processos psicológicos, indo além daqueles que delimitam os conceitos de "comportamento operante" e de "contingência".

Com maior especificidade ainda, de acordo com o conceito de variável, de graus de variável e das possibilidades de usar diferentes níveis de mensuração para especificar os graus em que uma variável pode apresentar (Rebelatto e col., 1987, pp. 175-198), o aspecto definidor de um comportamento operante é a relação entre graus (específicos ou faixas de variação dos mesmos) de cada uma das propriedades (ou aspectos) de atividades de uma classe e graus de cada uma das propriedades de eventos ambientais de uma ou mais classes (conforme sejam antecedentes ou subsequentes à atividade do organismo). Skinner (1969, p. 131), com um significado similar, denominou a "resposta" como "componente ou instância" de um operante que ele considerou como classe de eventos. Ainda é útil lembrar que "eventos ambientais" incluem tanto os que antecedem às ações de um organismo, quanto os que sucedem essas ações em diferentes períodos de tempo e até distâncias no espaço.

A complexidade do conceito como um conjunto de interações específicas envolve um ambiente em mudança. E qualquer um dos três tipos de componentes dessa relação é circunstancial: um evento é um estímulo somente se estiver em uma dada relação com alguma ação do organismo, uma ação só é uma resposta se estiver em uma dada relação com algo que acontece no ambiente que a antecede (talvez não quando essa relação seja apenas de oportunidade para ocorrência da ação) e, por fim, um evento subsequente só é algo que possa ser chamado de estímulo subsequente ou consequente se houver alguma relação específica com a atividade apresentada pelo organismo. Sem essas relações, que não são necessárias ou obrigatórias, são circunstanciais ou contingências, eles são eventos que não constituem uma interação. Por isso, surge o nome "tríplice contingência": a ocorrência dos três tipos de eventos em uma interação específica, ou fora dela, não é algo necessário, fixo ou obrigatório, mas quando acontecem em interação, configuram ou começam a configurar um outro evento mais complexo que qualquer um dos três eventos isolados. As interações entre eles, porém, é um sistema complexo e não absolutamente estável e foram elas o objeto de estudo dos analistas experimentais do comportamento, durante décadas. Os eventos e as interações que constituem um operante são contingências, mas o sistema com as características delimitadas pelo tipo de evento subsequente que as constitui é uma "contingência de reforçamento" (ver Skinner, 1969). E essa diferença pode ser crucial para entender e lidar com o que ficou denominado como "comportamento operante".

Catania (1973) indicou, ainda, que a especificação das classes de "estímulos" e das classes de "respostas" exige que sejam delimitados, também, os tipos de relações comportamentais das quais essas classes podem fazer parte. "Podem fazer parte" (circunstância ou contingência) é diferente de "necessariamente fazerem parte", ou "sempre serem parte de". O autor considerou que o conceito de comportamento operante mantinha, até então, uma ênfase maior nas classes de "respostas" do que nas propriedades da interação entre respostas e estímulos. Catania salientou que foi estabelecida uma dicotomização entre "respondentes" (classes de respostas definidas em termos dos estímulos que as eliciavam) e operantes (classes de respostas definidas em termos dos estímulos que elas produziam). Catania 
ainda esclareceu que, nessa dicotomia, está implícita outra e, talvez mais importante (ou equivocada?), distinção entre duas classes complementares de interações comportamentais: interações reflexas e interações operantes. Classes complementares porque ambas estão envolvidas na constituição e, como classes, são importantes para a identificação e descrição de uma unidade comportamental.

Sem estarem em interações específicas entre si não parece caber denominar quaisquer eventos de "estímulos" ou "respostas". O problema maior, porém, parece estar no fenômeno que é constituído pelas interações entre esses tipos de eventos. Diferentes autores (Skinner, Staddon, Schick, Catania, Ribes, Bolles, Seligman...) salientaram, de formas diversas, a importância de distinguir, com clareza, critérios utilizados para delimitar uma interação comportamental (uma unidade de comportamento): é possível referir-se ao que o organismo faz de uma maneira descritiva das características físicas dessas ações ou de uma maneira funcional pelas características das relações entre aquilo que o organismo faze o ambiente em que o faz. Considerando a complexidade que tais interações podem ter, depois de quase um século de produção de conhecimento, há uma ainda grande quantidade de esclarecimentos a produzir e uma complexidade também grande do fenômeno "comportamento" a levar em conta na sua análise do que parece ser feito corriqueiramente no trabalho com o comportamento. Isso tudo, como percepção e como possibilidade, é mais do que, com o conhecimento disponível, era possível fazer nas três décadas depois das primeiras descobertas de Skinner a respeito da interação denominada por "operação do organismo no ambiente" e suas decorrências para as múltiplas relações das atividades desse organismo com seu ambiente.

A análise (literalmente, a especificação das partes componentes de um todo) de um fenômeno com tal complexidade exige que seus constituintes sejam muito bem especificados, assim como as interações estabelecidas entre eles em cada situação em que ocorrem. A mera especulação ou o mais elaborado raciocínio não serão suficientes para dar conta dessa análise e de sua verificação e demonstração inequívoca. Impõe-se um método de verificação e demonstração que possa auxiliar a explicitar o que constitui cada relação e, com isso, viabilizar a construção do fenômeno complexo a partir de suas partes constituintes. A possibilidade de síntese comportamental (desenvolvimento, instalação, ensino, correção...), um termo já utilizado por Ferster e col. (1975), também a ser verificada experimentalmente e demonstrada de maneira inequívoca, surge como algo no horizonte do trabalho de analistas do comportamento. Isso vai ao encontro da frase-título do artigo de Baer (1973): in the beginning there was the response. Inaugurado o século XXI, o desenvolvimento de comportamentos operantes de valor na sociedade com uma compreensão das interações que constituem uma unidade de comportamento como uma relação forte (em graus variados) entre seus componentes é algo já viável, conforme demonstra o conhecimento disponível. Assim como é viável o manejo de variáveis que interferem no estabelecimento dessa relação, como determinantes ou intervenientes no estabelecimento de cada unidade de um sistema de interações que constituam comportamentos.

As contribuições indicadas mostram a necessidade de utilizar com muita precisão e especificidade termos só aparentemente sinônimos ou equivalentes como: resposta, classe de respostas, comportamento, classe de comportamentos e comportamento operante. $\mathrm{Ou}$ estímulo, classe de estímulos, estímulos antecedentes, condições antecedentes. Ou, também, estímulos consequentes, estímulos subsequentes, consequências. Ou, ainda, sequência de respostas e cadeias comportamentais. Precisão e especificidade necessárias tanto quanto a: produto, resultado, reforço e reforçamento. Algumas vezes essas palavras referem-se a eventos simples e isolados; outras a interações específicas entre eventos de determinado tipo, o que, em si, constitui outro objeto de referência ou de estudo. Parece fundamental deixar claro a que aspecto específico do sistema de interações que compõem um comportamento cada termo se refere e ao que está efetivamente sendo abrigado como eventos componentes ou como determinantes da classe de eventos a que cada termo faz referência. Ainda mais quando ele é a denominação de uma interação ou de um sistema específico de interações entre classes de eventos.

Esses exames, análises e questões estabelecem uma espécie de demarcação de uma mudança no que era concebido como comportamento até Skinner 
propor o conceito e demonstrar a existência do comportamento operante e os autores citados, ele incluído, apresentarem os problemas indicados. Essa mudança é fruto de contribuições específicas de múltiplos cientistas e profissionais da análise do comportamento em várias modalidades de trabalho com o comportamento dos organismos vivos. Para a Análise do Comportamento, porém, muitas perguntas ainda permanecem sem resposta e, se for considerado que o comportamento operante é uma interação específica entre as características do que o organismo faz com as do ambiente em que o faz, novas perguntas precisam ser formuladas: a) que tipos de relações existem (ou podem existir) entre os três componentes de uma unidade comportamental? b) como identificálas e nomeá-las? c) como analisá-las? d) quais critérios utilizar para delimitar uma unidade de comportamento, tanto quando ampla como quando é específica - ou restrita -? e) como relacionar os conceitos de classe e cadeia de comportamentos com a delimitação de uma unidade comportamental? f) como relacionar e trabalhar com classes de comportamentos que englobam muitas outras classes de comportamentos mais específicos? g) como integrar o conceito de cadeias comportamentais com alternativas de encadeamento quando a "cadeia" é considerada uma unidade comportamental? Imagine-se "escovar os dentes" como uma unidade comportamental e já haverá uma complexidade grande para responder a todas essas perguntas. Em síntese: o que é nuclear e delimitador de cada um desses conceitos no trabalho com o comportamento?

Se for acrescentado a essas indagações e aos problemas que elas podem representar, o exame dos conceitos de "contingência" e de "contingência de reforçamento" ainda haverá mais exigências para a delimitação de uma unidade de comportamento operante. $\mathrm{Ou}$ no que constitui um sistema composto por várias unidades de comportamentos, mesmo em diferentes formas de entender um processo comportamental. É necessário ir além do que foi examinado até este ponto a partir da indicação de que ocorrem múltiplas interações entre diferentes valores das diversas variáveis que compõem cada um dos diferentes componentes (ou "instâncias") de qualquer unidade comportamental, seja ela ampla, específica, uma cadeia comportamental (ou várias ou com ramificações) ou uma classe de comportamentos em qualquer amplitude de abrangência.

Os dois conceitos (ou problemas?) indicados até aqui (conceito de comportamento e de contingência de reforçamento) parecem ainda exigir uma sistematização conceitual que vá além do que era considerado a respeito do comportamento, particularmente o humano, até a década de 1970, em Psicologia. Keller (1965/1970), em relação a isso, usa uma analogia coerente com as afirmações de Skinner (1953/1974, p. 21), quando realça o dinamismo que os problemas e controvérsias da Psicologia representam no âmbito da análise do comportamento. Keller esclarece, em seu conhecido estilo coloquial: “(...) é uma tentativa sincera e cabal de manter a casa da Psicologia em ordem: de repor essa peça do mobiliário, de reparar aquela; de indicar a aparência fora de moda de uma sala ou a nudez de outra; acrescentar uma ala aqui ou um andar ali; e, se necessário, de pôr a casa abaixo e construir uma nova - sempre de acordo com a quantidade, a necessidade e as posses de seus ocupantes" (Keller, 1965/1970, p.141). Talvez fosse necessário acrescentar "e conforme o repertório comportamental de seus ocupantes".

Trocando "móveis", "sala", “ala", "casa" por "fatos", "descobertas" ou "conceitos" a respeito de comportamento é possível ter uma noção do que seja o trabalho de cada um no empreendimento que é fazer Ciência e construir o conhecimento em Psicologia. Particularmente, em Análise do Comportamento, ao destacar a importância de esclarecer o que foi feito e examinado a respeito do ainda controvertido conceito de comportamento. Sempre considerando as contribuições a respeito do complemento "operante" que Skinner descobriu e formulou e que marcou uma grande diferença de uma noção genérica de comportamento como sinônimo apenas de atividade de qualquer organismo vivo.

\section{O CONCEITO DE COMPORTAMENTO DEPOIS DA CONFIGURAÇÃO DO COMPORTAMENTO OPERANTE COMO UM TIPO PARTICULAR DE INTERAÇÃO ENTRE ATIVIDADE DE UM ORGANISMO E AMBIENTE SUBSEQUENTE A ESSA ATIVIDADE}

No que resultaram esses esforços, pesquisas e conceituações no trabalho dos analistas de comportamento, além das controvérsias, questionamentos e reformulações conceituais? 
Destacando que, como qualquer evento, o comportamento pode ser definido de diferentes maneiras, cada estágio ou tipo de contribuição dos cientistas e profissionais que testam os conceitos existentes trazem possibilidades de inovação, nem sempre completas, boas ou adequadas. Mas, sempre tornando mais visíveis os problemas existentes por meio dos conceitos disponíveis e propiciando aperfeiçoamentos em tipos e graus diversos. Conforme as condições de conhecimento existente para cada um, de trabalho realizado, de instrumental disponível, de método ou técnicas utilizados, de referencial adotado, além do próprio repertório geral de cada pessoa, as definições podem ser construídas de diferentes maneiras. Em relação ao comportamento (ao "fazer") das pessoas (e de outros organismos vivos) acontece o mesmo. Ele pode ser definido ou conceituado de diferentes maneiras e, conforme o que for considerado nessa definição, ele vai ser entendido, estudado e utilizado de formas variadas.

Não se trata de uma interação genérica ou qualquer relação entre o organismo e o ambiente. Trata-se de um tipo de interação específica e isso é fundamental. Troca de calor, por exemplo, é uma relação entre organismo e ambiente, mas não é do âmbito da Psicologia. A diferença não é pouca e isso precisa ser bem entendido até antes de identificar quais os resultados específicos de cada tipo de interação entre cada tipo de aspecto envolvido na interação específica que está sendo objeto de exame como central ou nuclear para o conceito de comportamento operante.

Todorov (2012), afirma que não vê "razão para definir comportamento como interação entre organismo e ambiente como tem acontecido em algumas publicações e pode ser visto em alguns sites da internet". O autor tem razão. Se comportamento for entendido dessa forma, ele é objeto de estudo de várias outras áreas e objeto de intervenção em muitos campos de atuação. A queda de uma pedra na cabeça de uma pessoa ou a decomposição de um organismo morto seriam comportamentos de acordo com essa definição. Em ambos os casos há uma interação entre organismo e ambiente. Mas não a que possa receber a denominação de comportamento operante. A interação em foco na Psicologia exige a atividade do organismo como parte do processo de passagem de um ambiente que antecede essa atividade para outro que a sucede. Descobrir esses três elementos e de que maneira interagem é o núcleo do problema para trabalhar com o comportamento operante.

De forma similar, os exemplos de verbos isolados (salivar, correr, pular...) não são denominações de comportamentos, mas de classes muito amplas de atividades. "Fugir de um cachorro" é uma denominação (apenas uma denominação e ainda não uma caracterização) mais apropriada (ou aproximada?) para um comportamento específico que indica mais do que a atividade do organismo. Indica uma interação que está sendo estabelecida entre a presença, proximidade ou a atividade de um cachorro e a atividade de correr feita por uma criança, por exemplo, com a consequência de afastar-se do cão e evitar o risco (diminuir a probabilidade) de uma mordida ou ataque ou, pelo menos, diminuir as reações desconfortáveis típicas de ansiedade perante aspectos aversivos de uma situação. O que está sendo nomeado como comportamento de alguém é mais do que a atividade de correr. E não se trata de supor que o cão é a "causa" do correr ou que este ocorre porque tem a “distância do cão" como "causa"... O (ambiente) cão, o rosnar do cão, ou as características do cão podem ter múltiplos papéis ou funções em relação ao correr. E não parece adequado nomear apenas a "atividade de correr" como um comportamento, pelo menos depois do conceito de operante. Pelo menos pode não ser adequado sem saber mais a respeito da interação entre as características de tal atividade, as características do ambiente em que ocorrem e as características do ambiente que se seguem às atividades com tais características. E tal interação é muito diferente de "relação entre organismo e ambiente". No exemplo em exame, inclusive, a "contingência de reforçamento" poderia ser denominada de "reforçamento negativo" e a classe de comportamento operante (ampla) denominada de "fuga" (ou "fugir de um evento aversivo", um cachorro ameaçador). Se houver mais detalhes específicos do que ocorre nas circunstâncias que o exemplo ilustra, será possível denominar melhor os componentes, a interação e a contingência de reforçamento que configura as circunstâncias que possibilitam uma denominação ser adequada.

Oitenta e cinco anos depois dos questionamentos de Russell (1927/1969), o exame do que constitui o comportamento operante não pode deixar de lado os estudos que especificaram, muito além do manifesto 
behaviorista, o que foi paulatinamente desenvolvido para entender melhor um tipo de interação específica dos organismos vivos com o ambiente, denominado de "comportamento operante". É fundamental realizar uma extensa avaliação e integração das contribuições do trabalho de Skinner e colaboradores, ao longo de muitos anos, verificando, avaliando e demonstrando essas interações. Cientistas que, como parte das contribuições, criaram um sistema conceitual que possibilitou o entendimento dessas interações, complexas, fluidas e circunstanciais (constituídas por contingências), entre (é necessário destacar e insistir) características (ou graus de variáveis) das atividades de um organismo, com graus das variáveis que constituem o "ambiente" antecedente (ou concomitante com tais atividades) e os graus das variáveis que constituem o "ambiente" que se segue às mesmas atividades. Assim como também contribuíram para viabilizar o trabalho de intervenção com esse tipo de interações.

Dizer que "operante" é uma forma de comportamento (Todorov, 2013) e dizer que "sua definição como a interação da qual faz parte parece vir de uma confusão entre efeito e consequência", e completar com um exemplo que "um mero aceno de mão tem como efeito o deslocamento do ar, alguém acenando de volta é a consequência" parece ser insuficiente em relação ao que se evidencia a respeito da diferença entre atividade do organismo e suas interações com os aspectos do meio no qual, de alguma forma, essa atividade configura uma interação específica. Os próprios conceitos de "estímulo", "resposta" e "subsequência" (para não confundir o que se segue a uma resposta com "consequência" da mesma) são contingências ou eventos circunstanciais: dependem um do outro para ser o que estão recebendo como denominação, nesses casos. Vale relembrar: um evento só é estímulo se estiver em uma específica interação com uma resposta; uma atividade de um organismo só é resposta se estiver em uma também específica interação com um evento que a antecede. E, ainda, um evento só é subsequente se estiver em outra específica interação temporal com a atividade de um organismo. O mesmo pode ser dito a respeito de "consequência", outra interação específica com alguma atividade do organismo. Assim como pode ser dito da palavra "efeito", que não mais parece ser muito útil, em função das noções de "causa" e "efeito" na Ciência contemporânea, conforme exame de Lewin (1935/1975). Por isso, tais conceitos são considerados "contingências" (eventos circunstanciais) no sentido que podem ser o que denominam, mas também podem não ser, dependendo do conjunto de circunstâncias em que ocorrem. O próprio uso do termo "contingente" como sinônimo de "contíguo" é um equívoco. "Contingência" é sinônimo de "circunstancial" e não de "contíguo" ou "imediato" conforme aparece com frequência em publicações de Psicologia. "Contingente" é o que pode ser (ou acontecer) e pode não ser (ou não acontecer), é algo contrário a "necessário" (ou "fixo"). É sinônimo de circunstancial ou algo que "para ser" (ou ocorrer) depende de circunstâncias outras. Se elas variarem, um evento poderá ser outra coisa do que o inicialmente denominado (ver definição de contingência em Branquinho, Murcho e Gomes, 2006, pp. 208-209, ou outros dicionários de Filosofia e mesmo de tradução do inglês "contingent" para o português, pelo menos do Brasil).

Parece ser inócuo ou improdutivo um debate ou exame dessas possibilidades de definição sem um exame cuidadoso dos termos que constituem ou estão envolvidos com o conceito "comportamento" (dos organismos vivos), pelo menos desde o surgimento de seu complemento "operante". E, mais ainda, quando ele começa a ser entendido como "outra parte", complementar ao que era conhecido, até então, como "comportamento reflexo". E não mais, apenas, como "outro tipo de comportamento". Skinner em sua obra, em várias oportunidades, parece complementar e ir além das concepções que reduziam o comportamento a uma parte das interações das atividades dos organismos vivos e os ambientes existentes e aqueles criados por essas atividades. Sem as descobertas de Skinner e outros autores que se seguiram e sem as questões suscitadas por eles, "comportamento" ainda poderia ser um nome genérico, usado por muitas áreas de conhecimento e muitos campos de atuação profissional. Não há porque, na Psicologia, não identificar e caracterizar o que é específico do "comportamento" como seu objeto de estudo. E isso não parece também reduzir-se a atividades ou "respostas" dos organismos vivos. A separação entre "comportamento reflexo" e "comportamento operante" como se fossem categorias estanques e absolutamente distintas e não integradas ou 
integráveis, parece não corresponder ao grau de desenvolvimento já alcançado no conhecimento a respeito dos comportamentos que podem ser denominados pelo termo "operante".

Um exemplo de terminologia, confusa, equivocada e imprecisa, aparentemente técnica e precisa, pode ser visto em um parágrafo de um relato de pesquisa publicado em 2003: “...para a Análise Experimental do Comportamento, o objeto de estudo é o comportamento, ou seja, as interações do organismo com o ambiente no qual ele vive. O homem modifica o ambiente, por meio da emissão de respostas e é modificado por ele através de consequências que suas respostas produzem no ambiente. Essas consequências alteram a probabilidade futura das respostas ocorrerem novamente. (...). Essa relação, que enfatiza o controle exercido pelas consequências sobre o comportamento, é denominada comportamento operante e o processo no qual uma resposta produz determinada consequência e esta altera a probabilidade futura dessa resposta ocorrer novamente é denominado reforçamento" (por razões óbvias, não será identificada a obra). O que está destacado entre aspas não corresponde aos conceitos como estão sendo formulados neste texto e são, nessas frases, usados em sentidos diversos em locais diferentes das próprias frases. Em primeiro lugar, o comportamento não é "as interações do organismo com o ambiente no qual ele vive", a não ser que se esteja falando de qualquer atividade de qualquer substância existente. Como a referência é ao comportamento operante, no âmbito da Psicologia, as interações são mais específicas e não todas as interações. São apenas aquelas entre as atividades ou ações do organismo e o ambiente em que ele está durante e depois de sua atuação. "Modificado por ele" (o ambiente), também fica no mesmo universo genérico. A ingestão de alimento modifica o corpo humano... mas é mais do que um fenômeno psicológico... e as modificações são múltiplas (a curso, a médio, a longo prazo, percebidas pelo organismo de imediato, ou não associadas por ele a propriedades específicas dos alimentos ingeridos ou à forma de ingeri-los etc.). A palavra "consequência" também precisa ser usada com mais cuidado. O que afeta não o organismo (no sentido físico, embora possa também envolver isso), mas as características de suas atividades e de suas interações com o ambiente são os eventos que se seguem às suas ações ou atividades imediatamente ou proximamente. E que podem apenas ser concomitantes, seguir-se ou ser contíguos a essas ações ou atividades. Não seriam "consequências" propriamente ditas (nem "efeitos" ou "decorrências") nem necessárias e poderiam alterar a probabilidade de ocorrência de novas ações similares (da mesma classe) em situações com propriedades também similares àquelas em que ocorreram as ações anteriores. Nesta última condição, com maior probabilidade, podem ser "respostas" a determinadas propriedades do ambiente em que as ações anteriores foram apresentadas, desde que haja alguma interação entre essas propriedades e novas ações similares às anteriores. Um evento pode ser apenas a ocasião em que uma ação é realizada. Ele só se transforma em estímulo antecedente quando já é mais do que "ser apenas ocasião" quando ocorre alguma atividade de um organismo vivo: indicador, provocador, sinalizador etc. em relação à ação do organismo, mesmo que em condições fracas ou precárias. Nessas circunstâncias ele começa a poder ser denominado de "estímulo" e a ação ou atividade do organismo de "resposta". Algo similar ocorre, quando o organismo estabelece alguma interação com alguma das propriedades do ambiente que ocorrem em seguida, junto ou contiguamente por meio de uma atividade que apresenta: para o organismo elas "parecerão ser consequência", embora possa ser apenas algo que é contíguo no tempo e ou no espaço. E passará a exercer controle sobre a probabilidade de novas ações da mesma classe e reforçará (fortalecerá) a interação que o organismo está estabelecendo entre suas ações, algum (ou alguns) aspecto do ambiente no qual realizou (diferentemente de "emitiu”) alguma ação ou atividade e o que aconteceu em seguida à sua ação. O que faz com que mude a probabilidade de ocorrência de novas atividades do mesmo tipo (ou classe) no futuro e altere a força das relações entre os aspectos do ambiente (antecedente às ações e subsequentes a elas) é o que constituirá não mais o comportamento operante, mas as contingências de reforçamento desse tipo (ou classe) de comportamento (das interações específicas que estão sendo destacadas como componentes de um comportamento). É, pode ser dito, a interação do que é "consequência" do que se segue à atividade do organismo nas interações desse organismo com aspectos de seu ambiente e na probabilidade de novas ocorrências das atividades 
da mesma classe em situações similares. Reduzir tudo isso a uma genérica "relação entre organismo e ambiente no qual ele vive" equivale a quase anular o conhecimento desenvolvido pela Análise do Comportamento ou, pelo menos grande e importante parte dele. O texto apresentado é um conjunto de equívocos.

Tais imprecisões podem parecer inócuas, mas a literatura já registra que a "consequência" definidora de um comportamento operante muitas vezes está distante temporalmente da apresentação ou realização da ação de um organismo e o que funciona, pelo menos inicialmente, como "reforçador" é o evento que acontece contiguamente (e circunstancialmente) a essa ação. Para o organismo pode parecer ou "funcionar" como "consequência", mas o conceito, para um analista de comportamento denominar uma unidade de operante necessita ser preciso e usado de forma adequada ao que está acontecendo e não ao que parece ou aparece ao organismo que se comporta. O exemplo citado no parágrafo anterior é apenas ilustrativo. Mas é rico em sutilezas da imprecisão ou ambiguidade com que, inadvertidamente, é possível perceber, ler, falar ou escrever a respeito desse fenômeno.

Os componentes de uma definição de comportamento operante - o que é uma maneira de entender tal tipo de fenômeno - precisam ser delimitados com muita clareza, precisão e estabilidade. Assim como o uso dessas definições e dos nomes dados a qualquer comportamento em situações de estudo ou de intervenção. Por exemplo, a cada circunstância: o que está sendo ambiente? Quais aspectos do ambiente estão participando do que está relacionado com a ocorrência de uma atividade de um organismo? De que maneira estão participando? Falar ou escrever "emitir uma resposta" já pode envolver o que o organismo está fazendo com uma "entidade interna" e não com o ambiente? Não seria mais correto falar ou escrever "apresentar uma ação ou atividade" até poder dizer que o organismo está apresentando uma "resposta" a algo (quando essa relação estiver estabelecida e verificada)? Isso é apenas o começo dos problemas com os conceitos. A própria percepção e maneira de falar dos aspectos dos ambientes existentes e subsequentes ou consequentes à atividade do organismo já trazem consigo várias complicações a serem resolvidas e que ainda não parecem ser algo que esteja suficientemente bem estabelecido coletivamente no âmbito da Análise do Comportamento. Desempenho e resposta, também como exemplo, são termos que tem referenciais diferentes de atividade ou ação. E, no entanto, isso aparece indiscriminadamente em vários artigos da área. Outros conceitos (já citados) correm o risco de não estarem sendo usados de forma coerente com uma concepção delimitada (e coletiva?) de comportamento.

O questionamento e o exame feito por Micheletto (1997), por exemplo, é mais uma contribuição que leva à necessidade de maior clareza no uso desses termos. Não é irrelevante a pergunta “o sujeito faz parte de seu próprio ambiente?". De forma similar perguntar: o ambiente é parte ou não do comportamento? Qualquer complemento colocado em um verbo já configura uma interação como parte da delimitação de um comportamento, por ser esse um processo que não acontece em um vácuo. Não é adequado ou suficiente nomear comportamentos apenas com verbos. Eles sempre exigem um complemento que se refira ao contexto em que ocorre a ação que o verbo denomina. Fazer isso de maneira clara e completa a ponto de entender de que maneira específica um determinado organismo está se relacionando com determinados aspectos de "seus ambientes" por meio de quais características de suas ações é algo que está na base, no núcleo e na origem da Análise Experimental do Comportamento, uma maneira de estudar que viabilizou, progressivamente, uma grande visibilidade a respeito dos componentes de uma complexa interação entre o "fazer" de um organismo e as circunstâncias em que esse fazer ocorre, incluindo o que tais circunstâncias alteram nesse "fazer". O exame de Baum (2002) a respeito das dificuldades existentes com a mistura entre percepções (e denominações?) molares e moleculares no exame do comportamento são também contribuições na direção de um exame mais completo e minucioso das circunstâncias que constituem uma interação entre estímulos existentes, atividades do organismo e estímulos efetivamente consequentes de suas ações (ou apenas sequenciais a elas). Onde exatamente estão os limites desses conceitos? Quais e quantas interações eles constituem em cada circunstância de sua ocorrência? Simonassi e col. (2010) e Simonassi e col. (2012) reiteram a importância desse exame 
em si e para a compreensão da abrangência do papel do reforço no repertório comportamental de um organismo (Simonassi e col. 2011). O exame de Micheletto acarreta várias questões ao considerar a possibilidade de o que aconteça no corpo de um organismo possa ser parte de seu comportamento como "ambiente" em relação ao qual ele realiza uma atividade. Tal exame pode ser ainda mais explorado como contribuição para identificar e entender as interações que constituem um "operante".

FUnÇÃo dE EVENTOS QUE SE SEGUEM À ATIVIDADE DO ORGANISMO EM RELAÇÃO ÀS INTERAÇÕES ENTRE OS TRÊS COMPONENTES DE UM OPERANTE: CONCEITOS DE "CONTINGÊNCIA"

E DE “CONTINGÊNCIA DE REFORÇAMENTO”

Até este ponto foram examinadas interações entre os componentes de um comportamento operante, mas elas ainda são mais complexas do que uma possível sequência de interações indo do antecedente para o subsequente à ação do que pode parecer à primeira vista para quem considera o significado estrito do termo "operar". O ambiente resultante, produzido, consequente ou subsequente à atividade do organismo também "opera" na atividade do organismo e nas suas interações com o ambiente. Há interação entre os componentes e isso significa a existência de relações recíprocas entre eles. De certa forma, evidenciou-se tal "parte do processo comportamental" com mais um conceito criado com a descoberta do que acontecia com as atividades de um organismo quando os eventos que se seguiam a elas tinham certas características. $\mathrm{O}$ conceito de "contingência de reforçamento" foi o que consolidou muito fortemente as integrações entre as múltiplas descobertas iniciadas com o trabalho precursor de Skinner. Mas, novamente, os conceitos precisam ser entendidos como conceitos que se referem a interações específicas entre eventos e não a eventos particulares ou fixos em suas propriedades ou características. Skinner (1969) apresentou um aprofundamento (ou uma sistematização) desse conceito em "Contingencies of reinforcement - a theoretical analysis", embora o texto contenha vários problemas em sua organização e destaques que podem confundir conceitos de "operante" (como "fuga" e "esquiva", denominações de duas classes gerais de comportamentos: "fugir" e "esquivar", com todas as variações possíveis) com o conceito de "contingência de reforçamento". No caso dos exemplos de "fugir ou esquivar de algo", tais classes de operantes são fortalecidas por "contingências de reforçamento negativo": o organismo evita ou foge (evita, reduz, elimina) de algo aversivo por meio de algum tipo de atividade dessas duas classes de operantes.

Importa distinguir que "contingência" e "contingência de reforçamento" não são sinônimos (ver Souza, 2000, para exame mais detalhado dessa diferença). E, no caso do comportamento operante, elas denominam propriedades muito diferentes dos eventos envolvidos em uma unidade comportamental. O termo "contingência" é sinônimo de "circunstancial" e não de "contíguo" ou "imediato" ou de "consequência" e isso aparece indistintamente na literatura existente no país (incluindo as traduções), com uma frequência comprometedora dos conceitos da Análise Experimental do Comportamento (e é “do comportamento" por referir-se ao comportamento operante - uma categoria específica - e não "de comportamentos" por não referir-se a qualquer conceito de comportamento ou a atividades em geral de organismos variados, inclusive as substâncias, os átomos, os astros, os materiais etc.).

Um evento (pode ser um objeto ou uma propriedade dele), por exemplo, só é "estímulo" circunstancialmente. Isso significa que, conforme as circunstâncias o evento não está em uma relação (qualquer que seja: facilitadora, indutora, provocadora, sinalizadora etc.) com alguma atividade de um organismo vivo. $\mathrm{O}$ mesmo pode ser dito de uma atividade de um organismo. Para ser denominada de "resposta" ela precisa estar em uma determinada relação com algum aspecto do ambiente em que ocorre. Certas atividades - fisiológicas, por exemplo - de um organismo podem (o que significa "circunstancialmente") ser mais constantemente "respostas" a estímulos por constituírem o que Bolles (1970) e Seligman (1970) denominavam de "atividades típicas da espécie" ou de "preparação e contra-preparação" para a interação com o ambiente. Mas não são a regra e, embora constituam parte da interação comportamental, serão partes da "interação operante" depois de ocorrerem determinadas outras circunstâncias que vão além da simples relação estímulo-resposta (ver Catania, 1973). Por exemplo, 
o desconforto (ou conforto) percebido pelo organismo com uma atividade fisiológica, pode ser considerada consequência dessa "reação do organismo"? Se puder, há uma complexidade maior do que apenas uma reação fisiológica a um estímulo, mesmo que a frequência dessa resposta ainda permaneça como um problema a ser esclarecido para considerar os efeitos dessa "consequência" no organismo em relação à reação fisiológica. Mas, se a reação fisiológica for parte de uma cadeia comportamental, parte disso já estará em outro sistema de interações: a consequência (no organismo) poderá ser uma condição que facilitará ou até induzirá o organismo a apresentar outras atividades que, por sua vez, constituirão outras interações, talvez mais claramente operantes. $\mathrm{O}$ exame de sentimentos e emoções como processos comportamentais tem esse problema inerente a sua apresentação por um organismo. Eles geralmente são comportamentos complexos nos quais estão envolvidas tanto reações fisiológicas (incluindo o estado corporal decorrente, sua percepção pelo organismo e, até sua nomeação) quanto complexas cadeias de comportamentos que podem começar com o estímulo e a reação fisiológica, mas continuam produzindo condições que vão constituir outros comportamentos em seguida, estabelecendo "cadeias comportamentais" e não apenas "sequenciamento de respostas".

O mesmo pode ser dito dos eventos que se seguem à atividade de um organismo. Eles são circunstanciais. Sendo ou não imediatos, sendo ou não aversivos ou gratificantes, sendo eliminados ou produzidos, ocorrendo depois de uma cadeia de comportamentos (após o último elo de uma cadeia comportamental) etc. constituem uma parte da variedade de possibilidades de ocorrência desses eventos em relação às atividades de qualquer organismo e para cada organismo. Sua variação, porém, não necessariamente tira qualquer evento com qualquer dessas propriedades da interação das atividades de um organismo com seu ambiente. O tipo de interação entre os componentes de um comportamento e a força dessa interação (o quanto estão interligados e resistentes à ruptura dessa interligação) serão diferentes e isso é o que constituirá cada tipo de circunstância com seus efeitos na força ou resistência das interações entre os três tipos de componentes de um comportamento. "Reforçado" constituirá uma característica do conjunto de interações entre os três componentes, conforme as características dos eventos subsequentes à atividade de um organismo, e não da atividade do organismo a qual aumentou a probabilidade de ocorrência. A alteração na frequência de ocorrência das atividades de uma classe é uma evidência indicadora de que, provavelmente, há uma relação estabelecida entre três componentes com certo grau de força ou resistência, configurando uma unidade de "comportamento operante" com algum grau de estabilidade (ou força?) no conjunto ou sistema de interações da atividade de um dado organismo com um dado ambiente (ou um similar).

Para elucidar um pouco mais o conceito de operante e suas relações com o conceito de contingência de reforçamento, uma ilustração gráfica (uma fórmula básica?) pode auxiliar. Na Figura 1, estão indicadas várias relações (representadas pelas setas) que elucidam as várias possibilidades (circunstanciais, uma vez que dependem de outros eventos) para a função básica de cada um dos tipos de eventos que constituem as interações que estão sendo denominadas de "comportamento operante" e de "contingências de reforçamento". Cada seta representa um tipo ou classe de relação (podem ser vários conforme a especificidade) entre cada um dos tipos de eventos denominados no cabeçalho de cada uma das colunas na Figura 1.

O tipo de relação indicado pela seta na linha 1 do corpo da Figura 1, representa que algum evento (ou mais de um) está presente quando o organismo apresenta uma atividade e facilita, impede ou dificulta a ocorrência dessa atividade de alguma maneira. Qualquer uma dessas possibilidades pode existir antes que as demais relações ocorram.

O tipo de relação indicado pela seta na linha 2 , representa que algum evento se segue à atividade do organismo e ele tanto poderá "seguir-se a" apenas temporalmente, ocorrer simultaneamente, ser produzido pela atividade do organismo ou ser manejado por outro organismo. As características desse evento que se segue à atividade tanto podem ser aversivas, quanto ser agradáveis ao organismo em graus variados. Todas essas modalidades de eventos subsequentes também poderão variar no tempo, ocorrendo a cada vez que a atividade é realizada (em intervalos de tempo fixo ou variáveis), ou em 


\begin{tabular}{|c|c|c|c|}
\hline $\begin{array}{l}\text { Componentes } \\
\text { Tipos de } \\
\text { relação }\end{array}$ & $\begin{array}{c}\text { SITUAÇÃO ANTECEDENTE } \\
\text { (O que acontece antes ou junto } \\
\text { à atividade ou ação de um } \\
\text { organismo) }\end{array}$ & $\begin{array}{c}\text { AÇÃo } \\
\text { (OU ATIVIDADE) } \\
\text { (Aquilo que um } \\
\text { organismo faz) }\end{array}$ & $\begin{array}{c}\text { SITUAÇÃO } \\
\text { SUBSEQUENTE } \\
\text { (O que acontece depois da } \\
\text { ação ou atividade de um } \\
\text { organismo) }\end{array}$ \\
\hline 1 & - & $\longrightarrow$ & \\
\hline 2 & & 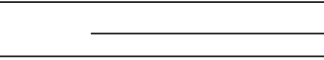 & $\rightarrow$ \\
\hline 3 & & 4 & 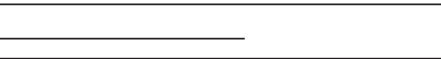 \\
\hline 4 & 4 & & - \\
\hline 5 & & & $\longrightarrow$ \\
\hline 6 & 4 & 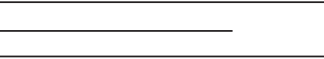 & \\
\hline \multirow[t]{3}{*}{7} & & $\longrightarrow$ & . \\
\hline & 4 & $\leftarrow$ & \\
\hline & $\longleftarrow$ & & \\
\hline
\end{tabular}

Figura 1. Diferentes tipos de relações básicas que podem estabelecer-se entre os três componentes de um comportamento operante, de tal forma que constituam um sistema complexo de inter-relações entre os mesmos, que, graças às características dos eventos consequentes serão as variadas "contingências de reforçamento", fazendo com que cada relação seja mais ou menos forte e a probabilidade de ocorrência das atividades de uma determinada classe ocorram com maior frequência ou sejam mais prováveis de serem apresentadas na situação em que o evento antecedente ocorrer ou estiver presente.

proporções fixas ou variadas quanto às unidades de atividade necessárias para sua ocorrência (Ferster e Skinner, 1957). Os eventos subsequentes também poderão ser físicos (no ambiente físico), sociais (atividades ou resultados de ações de outros organismos) ou fisiológicos (no corpo do organismo que apresenta a atividade). Em geral há várias subsequências para cada unidade de atividade de um organismo, embora ele possa não identificar (?) ou notar diferencialmente cada uma delas. Também poderá haver eventos que simplesmente nem sequer sejam notados (?) pelo organismo, mesmo quando imediatos à atividade apresentada por ele, ou não tenham importância de qualquer tipo para ele.

O tipo de relação representada pela seta na linha com o número 3 , indica que pode ocorrer uma alteração na atividade do organismo, conforme forem as características do evento subsequente a essa atividade. Ele pode fazer com que a atividade altere sua frequência, simplesmente por ocorrer, mesmo sem ser identificado (ou notado?) pelo organismo. Esse tipo de evento subsequente, porém, é particularmente importante por, ao fazer com que o organismo altere a probabilidade de apresentar atividade do mesmo tipo (ou classe), ele também influirá nas demais relações que serão estabelecidas entre a atividade do organismo e o ambiente antecedente a elas ou que ocorre quando elas são realizadas. Os eventos subsequentes poderão, dessa forma, ter múltiplos efeitos no sistema de relações ilustrados pelas setas apresentadas na Figura 1. Esses efeitos serão cruciais para entender qual interação está sendo fortalecida de alguma maneira ou em algum grau. Com o exame das próximas relações, isso ficará mais claro e será possível examinar mais aspectos da relação indicada na linha de número 3, na Figura 1.

A relação indicada pela seta na linha número 4 representa que os eventos subsequentes se relacionam com propriedades antecedentes à atividade do organismo, alterando o papel dessas propriedades. Essa relação pode alterar qualquer um dos tipos de relações indicadas para a relação representada pela seta na linha de número 1. Novamente, dependendo das características dos eventos subsequentes, essas propriedades serão modificadas de alguma forma ou em algum grau em relação à atividade (ou ação) do organismo.

$\mathrm{Na}$ relação representada pela seta na linha número 5, os aspectos (ou algum dos aspectos) da situação antecedente, torna-se algo "com algum 
significado" específico para o organismo: eles indicam (ou algum deles o faz), de alguma forma, o que especificamente acontecerá se o organismo apresentar uma atividade com determinadas características. Isso também pode fazer, por exemplo, que o organismo, diante de algo que sinalize que a subsequência de sua atividade será aversiva, faça outro tipo de atividade para evitar a situação aversiva que ocorreria se a atividade fosse a que sinaliza a possível ocorrência de algo aversivo subsequente à ação original. O ambiente existente, dependendo das características da subsequência, torna-se um sinalizador, que orienta, de alguma forma, a atividade do organismo. Se a relação anterior for de que ocorrerá um evento, subsequente à sua atividade, que seja eventualmente gratificante para o organismo, ele tenderá a realizar novamente a atividade que já foi seguida por esse tipo de evento. As variações do tipo de sinalização que os eventos antecedentes terão, dependerão das características dos eventos subsequentes à atividade do organismo. De qualquer forma, é mais um dos tipos de relações existentes entre a atividade de um organismo vivo e aspectos de seu ambiente e, embora, seja uma relação existente entre ambiente antecedente e subsequente, ela é forjada por meio da atividade do organismo na sua relação com os eventos subsequentes a essa atividade. Essa interação específica pode fazer com que um evento que originalmente era um antecedente, adquira propriedades semelhantes à consequência que se seguiu à atividade que a produziu na presença do que constituiu um "estímulo antecedente".

A relação simbolizada pela seta na linha de número 6 é uma espécie de decorrência das demais relações. A ocorrência da atividade do organismo fica influenciada (sob controle) de algum aspecto (ou mais de um) do ambiente antecedente a essa atividade. A tal ponto que é possível dizer que a atividade do organismo passa a ser (ou pode ser assim considerada) como uma "resposta" a esse (ou esses) aspecto do ambiente antecedente à atividade. E, também nesse caso, algum aspecto do ambiente (ou mais de um) poderá ser considerado como "estímulo". Isso pode chegar a um grau que possibilita considerar essa relação quase como a que era considerada "reflexo". O exemplo mais típico é quando o treinamento de um organismo (ou sua aprendizagem) desenvolveu relações tão fortes que ele "reage automaticamente", de forma imediata e de maneira estereotipada ao aspecto (ou aspectos) do ambiente que está relacionado com sua atividade. Há artistas ou esportistas (e outros profissionais) que não controlam algumas de suas "reações" perante certos aspectos de seu ambiente a tal ponto que, quando tais aspectos acontecem, a atividade usual do organismo é apresentada sem haver demora ou até sem controle (ou "percepção ou identificação") do organismo que a apresenta. Falar de "hábito" ou "impulso" ("vocação", "teimosia", "vício" são variantes disso) é regredir no conhecimento do que faz essa interação ocorrer dessa forma ou, pelo menos, encobrir muitos aspectos envolvidos nela.

Voltando à função (ou papel) de cada um dos tipos básicos das relações que podem existir entre os três componentes de um comportamento operante, elas podem participar das interações em diferentes funções ou intensidades conforme os efeitos da interação entre os eventos subsequentes e a frequência da atividade a que eles se seguem. A relação indicada na primeira linha, por exemplo, poderá tornar-se um estímulo sinalizador da ocorrência do evento subsequente, quando este último tiver ocorrido pelo menos uma vez após uma atividade específica do organismo. Ou poderá, depois de algumas ocorrências da interação entre a atividade e o evento subsequente, tornar-se um forte "indutor" dessa atividade, consolidandose em um papel de "estímulo discriminativo" para a apresentação da atividade em foco. Mas também, no caso de a consequência ter características opostas (for aversiva, por exemplo), ser um "estímulo sinalizador de que aquela atividade não deve ser apresentada". São as variações das características dos eventos subsequentes (que podem ser consequências imediatas ou não, sociais, físicas ou fisiológicas) que determinarão graus variados de probabilidade nas características das demais interações entre os três componentes e da força dessas interações.

A linha número 7 da Figura 1 reúne as múltiplas relações entre circunstâncias (aquilo que pode ou não ser ou acontecer) que constituem o que Skinner denominou de "contingências", cujo significado, desde a Filosofia Clássica até o que os dicionários de Filosofia contemporâneos e de tradução do inglês para o português consideram como significando "circunstancial" e não de ocorrência "necessária". Particularmente nos dicionários de Filosofia o sentido é "aquilo que pode ser e pode 
não ser", explicitando o que é apenas possível e não "necessário" (ou "obrigatório" em uma expressão mais comum). O exemplo clássico disso são os papéis sociais: alguém é marido, circunstancialmente, ou seja, somente na relação com outra pessoa (esposa). Fora dessa relação ele poderá ser amigo, colega, cliente, empregado, dirigente... todos também papéis contingentes ou circunstanciais. Isso quer dizer, que dependem de outras circunstâncias "para ser o que são". Ou para serem definidos como tais. É uma perspectiva de definir os eventos (papel social, nos exemplos ilustrativos) pela sua função, ou pelas relações que estabelecem com outros eventos. Por isso são denominados de "circunstanciais" ou "contingências". Em dadas condições eles são algo (ou tem uma função). Em outras condições (ou situações) serão outra coisa (ou terão outra função).

O que será usado para defini-los a cada momento é determinado pelas várias condições que controlam o comportamento de definir algo, inclusive, o repertório de comportamentos relacionados com os processos de definir eventos estudados no âmbito da Ciência e da Filosofia (particularmente da Lógica) como processos de conhecer (ou pelo estudo desses processos - metodologia). Por essas condições, um operante é delimitado pelo que foi denominado de "tríplice contingência". Os três componentes que entram nessas relações são, cada um deles, uma contingência ou, em termos leigos, são circunstanciais: dependem de outros eventos para estar na função em que estão. São definidos pelas relações que estabelecem com outros dois tipos de eventos com múltiplas variações e graus variados de possibilidades de ocorrência. As próprias condições do organismo podem ser estabelecedoras da função que pode ter qualquer desses eventos em um momento ou outro. Um organismo saciado pode defrontarse com um evento que sinaliza a disponibilidade de alimento, mas não apresentar a resposta de comer naquele momento. Isso faz com que o "estímulo" não tenha a mesma força de determinação da ocorrência da atividade de "comer" do organismo, nessa circunstância (ou contingência específica).

Algumas vezes, o termo "tríplice contingência" (ver o exame feito por Todorov, 1985) é utilizado como se fosse sinônimo de "contingência de reforçamento". No entanto, um evento é "reforçador" do sistema de relações entre esses três componentes de um comportamento quando se segue à atividade do organismo e altera esse sistema de relações, fortalecendo (ou enfraquecendo) essas relações de alguma forma ou em algum grau (o que é indicado pela relação da linha número 3 da Figura 1). "Reforçador", assim como a "operação ou o processo de reforçamento", são denominações de um evento ou do que ele faz no sistema de relações ao seguirse a uma atividade e produzir vários "efeitos" nas relações entre os três tipos de componentes. Um é o aumento da frequência da atividade a que ele se segue. Outro é o que pode ser deduzido desse aumento de frequência: uma maior probabilidade de que, nas mesmas circunstâncias ou contingências do ambiente, as atividades do mesmo tipo (ou classe) sejam apresentadas. Um terceiro é constituído pelas relações entre os três componentes ficarem mais fortes, melhor definidas e mais "estáveis". Um quarto, são alterações nas funções nos eventos que compõem o sistema de relações envolvidos em uma unidade de comportamento e em outros eventos que tenham algum tipo de relação com eles (similaridade, proximidade temporal ou espacial, às vezes propriedades opostas ou até abstratas - como tamanho relativo ou tempo decorrido entre eventos etc.). As contribuições de Baum (2002, 2004 e 2012) a respeito de "molar versus molecular" e de "alocação, indução e contingência" auxiliam a ter maior visibilidade a respeito dos problemas envolvidos na construção dessas interações.

As descobertas de Skinner, com as investigações no que ficou denominado por comportamento operante, caracterizaram bem as propriedades dessas relações entre as subsequências à atividade de um organismo e o sistema de interações entre os três componentes. Somente quando fica configurado o "papel" (ou função) daquilo que se segue à atividade do organismo é adequado falar em "contingências de reforçamento" (especificando qual é o tipo de contingência), não com o sentido de "eventos contíguos à atividade" ou que "se seguem a ela" mas que produzem um efeito de, "circunstancialmente ou contingentemente" e não "necessariamente", fortalecer determinados tipos de relações entre os três componentes. A função de evento reforçador para qualquer evento subsequente também não é algo fixo ou necessário, depende de várias condições que vão desde o aprendizado anterior, até as condições 
do organismo ou de operações ou condições estabelecedoras (atenuantes ou agravantes nos termos do trabalho no campo do Direito Penal, por exemplo) que alteram a função ou o papel das três circunstâncias básicas que constituem qualquer interação que recebe a denominação de "comportamento operante".

$\mathrm{O}$ exame das variações das contingências que podem ocorrer com cada um dos componentes de um operante sob os efeitos das variações dos eventos subsequentes não é objetivo deste texto. Isso exigiria um exame - e muitas investigações e demonstrações - do que pode ser abrangido pelo conceito de "equivalência" entre eventos (não apenas entre "classes de estímulos antecedentes"), particularmente no âmbito do comportamento dos organismos como aqui está sendo examinado. Obviamente não é objetivo, neste texto, realizar esse exame, o que, como foi indicado, demandaria uma grande quantidade de investigações e demonstrações até apresentar isso de forma suficientemente precisa e fundamentada.

Conforme acontecerem os três tipos de eventos, principalmente o que for subsequente à atividade do organismo, eles constituirão um ou outro comportamento e, qualquer que seja esse comportamento, a força das relações também será definida pelas circunstâncias existentes quando acontecer sua ocorrência. A contribuição importante disso tudo está em que a caracterização das relações entre atividade e eventos subsequentes, completou as relações entre os eventos antecedentes e a atividade do organismo e a alteração do ambiente após a atividade do organismo mostrou ter propriedades múltiplas que constroem ou delimitam as demais relações, tornando-as mais ou menos fortes (ou fortalecidas). E, "fortalecidas", nesse caso, também inclui uma variação em graus matemáticos que podem variar de "mais infinito" a "menos infinito". Deixando de lado a linguagem matemática, pode fortalecer ou enfraquecer o comportamento na dependência das variações das propriedades dos três componentes da interação em foco neste texto. São múltiplas interações e, no seu conjunto, são todas contingências ou eventos circunstanciais, que podem ou não ocorrer e podem variar de muitas formas.

Quando alguém aprende a "fazer uma incisão cirúrgica”, "apontar um lápis , “dirigir um automóvel", "consertar um computador", "escrever um texto demonstrativo", "manejar talheres em uma refeição", "construir argumentos" ou "construir falsos argumentos", "mentir", "decidir algo", "resolver um problema" ou "comportar-se eticamente", esse alguém está aprendendo interações entre aspectos do meio, atividades de seu corpo e produção de eventos que podem ser chamados de consequências ou resultados (à medida que são produzidos por suas atividades). Ele não está aprendendo apenas o que os verbos dessas expressões indicam. Nem é qualquer tipo de subsequência, mesmo que seja consequência, que delimita o que ele faz ou fez. Em qualquer desses exemplos, ele pode estar produzindo também resultados diversos do que aqueles que seriam desejáveis (e quais seriam, precisamente, esses resultados?) o que levaria a interações talvez inapropriadas com o ambiente e prejudicial até para a própria pessoa a médio ou longo prazos, o que ela pode não relacionar com sua atividade atual (ver os exames de Baum, 1999, 2002, 2004 e 2012 e Simonassi e col. 2010, 2011 e 2012, por exemplo). Descobrir o que está envolvido em cada um desses comportamentos assim denominados é uma exigência de análise e de verificação. Por isso, o próprio nome "Análise do Comportamento" (análise do operante em exame, que engloba esses três tipos de componentes) já indica um procedimento para caracterizar um comportamento importante: analisar e identificar as partes componentes (em relação). O termo "análise" nesse contexto não significa "exame" ou "avaliação". Significa fundamentalmente a identificação das partes de um sistema de interações entre componentes que precisam ser identificados, como uma primeira operação entre outras que configuram o trabalho dessa área de conhecimento e desse campo de atuação profissional.

E tal "análise" não pode ser feita com suposições ou observações superficiais. As exigências de método da área têm, como suporte, verificação e demonstração inequívoca (o método experimental e o nome "Experimental", indicativo na designação da área - é o horizonte ou orientação para essa exigência). Tal exigência é tanto no âmbito da investigação básica de como se dão essas relações e o que as afeta, quanto nos procedimentos de intervenção no comportamento dos organismos como construção ou desenvolvimento de novos comportamentos ou ainda como alteração de comportamentos existentes e prejudiciais ou incômodos. É por isso que, de certa 
forma, análise do comportamento (já na concepção de "operante"), intervenção, verificação e demonstração, são inseparáveis todo o tempo. Só depende de quanto é possível, por contingências (ou circunstâncias diversas), fazer isso de maneira adequada com os referenciais básicos da área em cada trabalho de um analista de comportamento. Obviamente, nessas contingências estão envolvidos o repertorio, o conhecimento e a preparação do profissional em qualquer das instâncias de trabalho na área, o que, em parte foi examinado por Holland (1978), quando considerou o comportamento do analista de comportamento como "parte do problema", em congruência com o que Sidman (1976) também levou em conta quando examinou o comportamento do cientista como parte do método científico e não algo fora dele.

É marcante no desenvolvimento do conhecimento em Análise do Comportamento a descoberta das funções (ou papéis) desses três componentes do comportamento na determinação da ocorrência de um comportamento específico. A consequência não "causa" o comportamento, mas, em certas circunstâncias, ela influenciará na força das relações e afetará a relação dos eventos antecedentes (a atividades de uma classe do organismo) com as atividades desse organismo. Um evento antecedente não, necessariamente, "causa" a ocorrência (ou a não apresentação) deuma atividade, mas se aproxima disso, à medida que sua relação com esse tipo de atividade é influenciada pela ocorrência de determinados tipos e condições dos eventos subsequentes. Os estudos a respeito de esquemas de reforçamento, por exemplo, são uma ilustração muito clara e expressiva quanto a mudar apenas uma ou duas das propriedades de ocorrência dos eventos subsequentes e produzir um poder de controle (determinação probabilística) na atividade do organismo com diferenças marcantes na frequência dessa atividade e na força das relações entre eventos antecedentes de uma classe e características das atividades do organismo (Ferster e Skinner, 1957; Skinner, 1969).

Quando Skinner (1969) exemplifica contingências de reforçamento, ele examina as interações entre os três componentes em função do tipo de consequência, e não "tipos de contingências de reforçamento". Por exemplo: "fuga" e "esquiva" (ou fugir e esquivar) são denominações de duas classes amplas de comportamentos operantes sob contingências de "reforçamento negativo". "Superstição" (ou comportamento supersticioso) também é a denominação de um tipo de interação entre os três componentes de um comportamento, quando as atividades de um organismo estão sendo mantidas em alta frequência com a ocorrência de um evento que apenas se segue a uma classe de atividades do organismo, sem ser produzida por essa atividade (ou, pelo menos, pode haver outro evento que não aquele a que o organismo está sob controle aparente). A contingência de reforçamento (aparente?), neste caso, é apenas incidental: um evento é concomitante ou apenas se segue sem ser produzido pela atividade do organismo. O "reforçamento" pode estar sendo produzido por outro evento que também se segue à atividade, mas não é tão aparente. Pelo menos com observação direta ou pelo próprio organismo que atua.

Em síntese, talvez seja importante destacar a pergunta: qual é a utilidade dos vários conceitos (examinados ao longo desse texto) se é possível referirse ao comportamento com a expressão "contingência de reforço"? Os diferentes tipos de contingências (circunstâncias) de reforço vão possibilitar identificar, analisar e entender o que mantém uma específica atividade em determinadas circunstâncias de eventos antecedentes a essa atividade quando há certos eventos que seguem a ela. Reforçamento positivo, reforçamento negativo, punição positiva e negativa e extinção parecem ser os tipos básicos de contingências de reforçamento capazes de fazer com que as interações entre os componentes de um comportamento sejam muito variadas na sua força em função das alterações na ocorrência dos eventos subsequentes às atividades do organismo.

Mesmo no caso do comportamento supersticioso, é arriscado dizer que o que mantém uma possível alta frequência de uma determinada atividade (ou classe de ação) do organismo sejam eventos subsequentes sem qualquer relação com as ações do organismo. As alterações fisiológicas (por exemplo, relacionadas à ansiedade) alteradas (e percebidas?), junto com o estado corporal (percebido?) quando um jogador faz um sinal religioso ou uma oração antes de um jogo podem ser eventos imediatamente subsequentes que "funcionam" como "consequência" pela relação de proximidade temporal ou espacial em que tudo acontece. $\mathrm{O}$ exemplo mereceria muito mais 
exame, mas também não é objetivo para este texto examinar tais exemplos e suas implicações para o trabalho de analistas de comportamento.

O que importa - e constitui o objetivo central deste texto - é destacar um pouco mais, o que já foi feito por diferentes autores problematizando vários aspectos dos conceitos da Análise do Comportamento, as possibilidades de localizar os conceitos de "comportamento operante" e de "contingência de reforçamento" como duas contribuições que alteraram (ou contribuíram para...) o que era considerado objeto de estudo e de intervenção da Psicologia e destacar umas poucas implicações para a terminologia e para cuidados a garantir no uso dessa terminologia. Algumas concepções, conceitos e decorrências nos procedimentos, desde a maneira de falar até a de intervir nos processos comportamentais, passando pelos estudos nas simulações de laboratório, mudaram ou precisam mudar com o desenvolvimento do conhecimento a respeito desses processos que são genericamente denominados de "comportamento", de "contingência" e de "reforçamento".

Talvez seja necessário prosseguir em um refinamento conceitual desses conceitos, sem criar modismos ou compensações conceituais para o que é pouco ou mal entendido nas decorrências para a atuação profissional e, mesmo, na literatura disponível. Uma literatura na qual, em muitos casos, é usada essa terminologia de maneira genérica ou conforme o uso que outros autores fizeram em diferentes momentos da história da Análise do Comportamento ou em condições de estudo diversas que possibilitavam uma utilização indiferenciada desses termos. O que não parece ser correto ou adequado quando há uma amplitude maior de exame da história de desenvolvimento da área de conhecimento e do campo de atuação profissional. Principalmente com o objetivo de utilizar esse conhecimento e a tecnologia que ele viabiliza de maneira cientificamente coerente e socialmente relevante, com a amplitude que cada um conseguir entender estas expressões.

\section{REFERÊNCIAS}

Baer, D. (1973). In the beginning there was the response. Em E. Ramp \& G. Semb(Orgs.) Behavior analysis: Áreas of research and application (pp. 16-30). New Jersey: Prentice-Hall.
Barlow, D. H., \& Hersen, M. (1984). Single case experimental designs - strategies for studying behavior change. New York: Pergamon Press.

Barlow, D. H., Hayes, S. C., \& Nelson, R. O. (1986). The scientist practitioner - research and accountability in clinical and educational settings. New York: Pergamon Press.

Baum, W.M. (2002). From molecular to molar: A paradigm shift in behavior analysis. Journal of the Experimental Analysis of Behavior, 78, 95-116.

Baum, W.M. (1999). Compreender o behaviorismo. Porto Alegre: Artmed. (T. A. Silva, M. A. Matos, G. Y. Tomanari, \& E. Z. Tourinho, Trads).

Baum, W. M. (2004). Molar and molecular views of choice. Behavioural Processes, 66, 349-359.

Baum, W. M. (2012). Rethinking reinforcement: Allocation, induction and contingency. Journal of the Experimental Analysis of Behavior, 97, 101124.

Bolles, R. C. (1970). Species-specific defense reactions and avoidance learning. Psychological Review, 77, 32-48.

Botomé, S. P. (1980). Objetivos comportamentais no ensino: a contribuição da Análise Experimental do Comportamento. Tese de doutorado não publicada. Instituto de Psicologia da Universidade de São Paulo, São Paulo.

Botomé, S.P. (2001). Sobre anoção de comportamento. Em H. P. de M. Feltes, \& U. Zilles, Filosofia: diálogo de horizontes. Porto Alegre: Editora da Pontifícia Universidade Católica de Porto Alegre e Caxias do Sul (RS) e Editora da Universidade de Caxias do Sul.

Branquinho, J., Murcho, D., \& Gomes, N. G. (2006). Enciclopédia de termos lógico filosóficos. São Paulo: Martins Fontes.

Capra, F. (1992). O ponto de mutação - a ciência, a sociedade e a cultura emergente. São Paulo: Cultrix.

Castro, L. (1975). Diseño experimental sin estadística. México: Trillas.

Catania, A. C. (1973). The concept of the operant in the analysis of behavior. Behaviorism, 1, 103-116. 
Daniels, A. C. (1989). Performance management: Improving quality productivity through positive reinforcement. Tucker: Performance Management Publications.

De Rose, J. C. (1997). Que é comportamento? Em R. A. Banaco. Sobre comportamento e cognição, Vol. 1. Aspectos teóricos, metodológicos e de formação em Análise do Comportamento e Terapia Cognitivista (pp. 79-81). Santo André: ARBytes.

Ferster, C. B., \& Skinner, B. F. (1957). Schedules of reinforcement. New York: Appleton-CenturyCrofts.

Ferster, C. B., \& Hammer Jr, C. E. (1975). Sintesis de los componentes de la conducta. aritmética. Em W. K. Honig (Ed.), Conducta operante: Investigación y aplicaciones (pp. 740-797). México: Trillas.

Holland, J. G. (1978). Behaviorism: Part of the problem or part of the solution? Journal of Applied Behavior Analysis, 11, 163-174.

Keller, F. S. (1970). A definição da Psicologia: uma introdução aos sistemas psicológicos ( $\mathrm{R}$. Azzi, Trad.). São Paulo: Herder. (Obra original publicada em 1965)

Lewin, K. (1975). O conflito entre os modos Aristotélico e Galilêico de pensamento na Psicologia Contemporânea. Em K. Lewin, Teoria dinâmica da personalidade (A. Cabral, Trad.). São Paulo: Cultrix. (Obra original publicada em 1935)

Merleau-Ponty, M. (1975). A estrutura do comportamento (J. A. Correa, Trad.). Belo Horizonte: Interlivros. (Obra original publicada em 1972).

Micheletto, N. (1997). Há um lugar para o ambiente? Em: Banaco, R. (Org.), Comportamento e Cognição, V. 1 (pp. 29-44). Santo André: ARBytes.

Pavlov, I. P. (1979). O reflexo condicionado. Em I. Pessotti (Org.), Pavlov. São Paulo: Atica. (Obra original publicada em 1934)

Rebelatto, J. R. \& Botomé, S.P. (1987) Fisioterapia no Brasil-perspectivas de evolução como campo profissional e como área de conhecimento. São Paulo: Manole.
Ribes, E. (1989). La psicologia: Algunas reflexiones sobre su qué, su como, su porqué y su para qué. Em J. Turbina (Ed.), El psicólogo (pp. 847-860). México: UNAM.

Ribes, E. (2000). Las psicologias y la definición de sus objetos de conocimiento. Revista Mexicana de Análisis de la Conducta, 26, 365-382.

Ribes, E. (2009). Reflexiones sobre la aplicación del conocimiento psicológico: Qué aplicar o cómo aplicar? Revista Mexicana de Análisis de la Conducta, 35, 3-17.

Russel, B. (1969). Delineamentos da Filosofia (Trad. de B Silveira, Trad.). Rio de Janeiro: Civilização Brasileira. (Obra original publicada em 1927)

Schick, K. (1971). Operants. Journal of the Experimental Analysis of Behavior, 15, 413-423.

Seligman, M. E. P. (1970). On the generality of the laws of learning. Psychological Review, 77, 406418.

Sério, T. M. A. P.(1983). Anoção de classe de respostas operante: sua formulação inicial. Dissertação de mestrado não publicada. Instituto de Psicologia da Universidade de São Paulo, São Paulo.

Sério, T. M. A. P., (1990). Um caso na história do método científico: do reflexo ao operante. Tese de doutorado não publicada. Instituto de Psicologia da Universidade de São Paulo, São Paulo.

Sidman, M. (1976). Táticas da pesquisa científica: avaliações dos dados experimentais na Psicologia. São Paulo: Brasiliense. Trad. de Maria Eunice Paiva. (Obra original publicada em 1960)

Simonassi, L. E., Cardoso, J. L. B., \& Santos, A. C. G. (2012). Porque a análise de Baum (2012): "rethinking reinforcement allocation, induction and contingency" é importante. Perspectivas em Análise do Comportamento, 3, 142-150.

Simonassi, L. E., Tizo, M., Xavier, V. P. P., \& Rocha, T. C. (2010). Sobre classes de operantes: os casos de nomeação e agrupamento. Psicologia IESB, 2, 13-15

Simonassi, L. E. Cameschi, C. E., Coelho, C., Coelho, 
A. E. V. B., \& Fernandes, E. C. (2011). Uma outra função do reforçador: organização/ordenação de comportamentos. Em C. V. B. B. Pessoa, C. E. Costa e M. F. Benvenuti (Orgs.). Comportamento em foco, Volume 1. (pp. 621-629). São Paulo: Associação Brasileira de Psicologia e Medicina Comportamental.

Skinner, B. F. (1931). The concept of the reflex in the descriptions of behavior. Journal of General Psychology, 5, 427-458.

Skinner, B. F. (1935). The generic nature of concepts of stimulus and response. Journal of General Psychology, 12, 40-65.

Skinner, B. F. (1938). The behavior of organisms. New York: Appleton-Century-Crofts.

Skinner, B. F. (1957). Verbal Behavior. New York: Appleton-Century-Crofts.

Skinner, B. F. (1969). Contingencies of reinforcement. New York: Appleton-Century-Crofts.

Skinner. B. F. (1974). Ciência e comportamento humano (J. C. Todorov, \& R. Azzi, Trad.) São Paulo: EDART e Editora da Universidade de São Paulo. (Obra original publicada em 1953)

Souza, D. G.(2000). O conceito de contingência: um enfoque histórico. Temas em Psicologia, 8, 124136

Staddon, J. E. R. (1969). Asymptotic behavior: The concept of the operant. Psychological Review, 79, 377-391.

Todorov, J. C. (1985). O conceito de contingência tríplice na análise do comportamento humano. Psicologia: Teoria e Pesquisa, 1, 75-88.

Todorov, J. C. (1989). A psicologia como estudo de interações. Psicologia: Teoria e Pesquisa, 5, 325347.

Todorov, J. C. (2002). A evolução do conceito de operante. Psicologia: Teoria e Pesquisa, 18, 123127.

Todorov, J. C. (2012). Sobre uma definição de comportamento. Perspectivas em Análise do Comportamento, 3, 32-37.

Todorov, J. C. (2013, 22 de outubro). Como definir comportamento. Retirado de http://jctodorov. Blogspot.com.br/2013/10como-definircomportamento.html.

Watson, J. B. (1913). Psychology as the behaviorists views it. Psychological Record, 20, 158-177. 